\title{
El impacto fiscal a la luz de los principios constitucionales del sistema tributario colombiano y la necesidad de moderar los beneficios tributarios en el impuesto sobre la renta
}

\author{
The fiscal impact in light of the \\ constitutional principles of the colombian \\ tax system and the need to moderate \\ income tax benefits
}

O impacto fiscal à luz dos princípios constitucionais do sistema fiscal colombiano e a necessidade de moderar os benefícios fiscais no imposto sobre $o$ rendimento

JuAn Gabriel Toro Londoño*

Politólogo, Universidad Pontificia Bolivariana; filosófo y abogado, Universidad de Antioquia; candidato a magíster en Derecho Penal, Universidad EAFIT.gabriel.toro@udea.edu.co, juan.toro26@gmail.com / https://orcid. org/0000-0001-6373-6101

Dor: https://doi.org/10.18601/16926722.n19.03 


\section{Resumen}

El propósito de este escrito es reflexionar sobre los principios constitucionales del sistema tributario, dado que la existencia de ciertos beneficios en el mismo, dispuestos por la legislación, se han vuelto un elemento distorsionante e inequitativo para la tributación. Para corregir esta particular forma de promover la regresividad, el Estado podría hacer una revisión de dichos beneficios o impulsar un gasto social más eficiente, de modo que debe contar con una carga tributaria más equitativa; es decir, para generar los efectos distributivos justos es fundamental que el sistema de financiamiento no sea regresivo, esto es, que no recaiga en mayor medida sobre las personas con menores ingresos. Esto obliga a pensar que el sistema tributario debería guardar un equilibrio razonable característico de un sistema fiscal exitoso, saludable, equitativo y racional. Por tanto, su racionalidad estaría asociada a la aplicación adecuada y conjunta de los principios constitucionales en la estructura tributaria en sus diferentes órdenes y no solamente a ciertos impuestos en particular. Evidentemente, los principios no bastan para reunir todas las condiciones de un sistema tributario racional, pero abarcan condiciones mínimas sin las cuales no es posible hablar de racionalidad en el mismo.

Palabras clave: principios constitucionales; sistema tributario; progresividad; regresividad; equidad; redistribución del ingreso; impacto fiscal; impuesto sobre la renta.

\section{Abstract}

The purpose of this paper is to reflect on the constitutional principles of the tax system, since the existence of certain benefits in it, specified by legislation, has become a distorting and inequitable element for taxation. To correct this way of promoting regressivity, the State could review these benefits or promote more efficient social spending, so that it must have a more equitable tax burden. That is, it is essential to generate the fair distributional effects that the financing system is not regressive, that is, that it does not fall more heavily on people with lower incomes. This forces us to think that the tax system should maintain a reasonable balance characteristic of a successful, healthy, equitable and rational tax system. Therefore, the rationality of the tax system related to the proper and joint application of these constitutional principles in the tax structure in its different orders and not only on taxes in particular. Obviously, the principles are not enough to meet all the conditions of a rational tax system, but they cover minimum conditions without which it is not possible to speak of rationality the tax system.

Key words: Constitutional principles; tax system; progressivity; regressivity; equity; income redistribution; tax impact; income tax. 


\section{Resumo}

O objectivo do presente documento é reflectir sobre os princípios constitucionais do sistema fiscal, dado que a existência de certos benefícios no seu interior, previstos pela legislação, se tornaram um elemento distorcedor e injusto para a tributação. A fim de corrigir esta forma particular de promover a regressividade, o Estado poderia rever estes benefícios ou promover despesas sociais mais eficientes, de modo a ter uma carga fiscal mais equitativa; por outras palavras, a fim de gerar efeitos distributivos justos, é essencial que o sistema de financiamento não seja regressivo, ou seja, que não recaia mais fortemente sobre as pessoas com rendimentos mais baixos. Isto significa que o sistema fiscal deve manter um equilíbrio razoável que é característico de um sistema fiscal bem sucedido, saudável, equitativo e racional. Por conseguinte, a racionalidade do sistema fiscal estaria associada à aplicação adequada e conjunta dos princípios constitucionais na estrutura fiscal nas suas diferentes ordens e não apenas nos impostos em particular. Obviamente, os princípios não são suficientes para satisfazer todas as condições de um sistema fiscal racional, mas abrangem condições mínimas sem as quais não é possível falar da racionalidade do sistema fiscal.

Palavras-chave: Princípios constitucionais; sistema fiscal; progressividade; regressividade; equidade; redistribuição do rendimento; impacto fiscal; imposto sobre o rendimento.

\section{Introducción}

Con cierta verdad se ha dicho que los impuestos en Colombia no son progresivos. Quienes piensan así tienen algún grado de razón cuando de forma comparativa examinan la renta de personas naturales de los países de la Organización para la Cooperación y el Desarrollo Económicos (OCDE $)^{1}$, que representa el $75 \%$ recaudado, y el impuesto sobre la renta de personas naturales en Colombia que, según se afirma, representa el $5 \%$ del total recaudado (Acosta, 2018). Si bien esta comparación pareciese revelar, en principio, que en Colombia la renta de personas naturales no es un impuesto realmente progresivo en razón de que con dicho recaudo no se podría cumplir de manera cabal con los amplios fines del Estado ni promover una práctica redistributiva que mitigue con seguridad la desigualdad, cierto es que la secuencia de este análisis no lograría explicar completamente el comportamiento favorable en los países de la OCDE, donde el índice Gini de la distribución del ingreso pasa de 0,47 a 0,30, mientras en Colombia permanece estático en 0,51 (Acosta, 2018).

1 Es una organización internacional compuesta a la fecha por 36 países cuyo objetivo es coordinar sus políticas económicas 
Ciertamente, este apunte inicial no menciona en su totalidad las causas del comportamiento negativo del coeficiente $\mathrm{Gini}^{2}$ en Colombia, esto es, la relación crecimiento económico-distribución del ingreso, por ser consecuencia de múltiples factores. Muchos de estos están relacionados directamente con las innovaciones tecnológicas, que cambiaron el patrón de crecimiento económico; con las políticas económicas, que no cumplen con el papel de mejorar la distribución; con los altos niveles de corrupción, entre muchos otros. Un cuadro completo asociaría la falla política y económica concerniente a los beneficios tributarios excesivos, las continuas reformas regresivas, la evasión y elusión fiscal, responsables en igual sentido de inequidad en materia tributaria. Lo anterior indica que incrementar la tarifa del impuesto de renta de personas naturales como solución propia al análisis fiscal de impacto no sería una salida definitiva, máxime en un contexto tributario generoso en beneficios, que no consulta de manera estructural la capacidad contributiva de los sujetos pasivos y es conocido, además, el anómalo crecimiento económico que concentra la renta.

El panorama es todavía más sombrío cuando con reiteración se afirma que el sistema tributario no es progresivo o equitativo verticalmente, pues, "quienes tienen mayor capacidad de pagar impuestos no aportan relativamente más que aquellos con menores rentas" (Acosta, 2018; Bautista, 2011; González y Corredor, 2016; DIAN, 2015a, p. 2). Innegable es que esta crítica no ha sido acogida por el legislador a causa de justificar varios fines económicos, entre estos: la generación de empleo, el desarrollo tecnológico, la promoción de sectores económicos determinados, el fomento a la inversión nacional o extranjera, el desarrollo de las regiones, la protección y conservación ambiental, entre otros. Esa falta de verticalidad aplica directamente cuando hablamos del impuesto sobre la renta de las personas naturales y también de los impuestos corporativos, pues, cuando se afirma que en Colombia la carga impositiva sobre las empresas es exageradamente alta, realmente se mira la tarifa nominal y no la tarifa efectiva, que es sobre la cual se tributa; esto es, donde se presenta el proceso de depuración encaminado a establecer en últimas la base gravable del contribuyente. Sobre tal base se aplica la tarifa fijada por la ley para obtener el impuesto básico que, a su vez, se afecta con descuentos tributarios para llegar finalmente al impuesto neto del contribuyente (DIAN, 2015a, p. 2).

Los tratos preferenciales que afectan la base gravable se reflejan en tres grandes rubros que intervienen en dicho proceso de depuración: los ingresos no constitutivos de renta, las deducciones y las rentas exentas, mientras los descuentos tributarios afectan directamente el monto del impuesto de renta que se liquida (DIAN, 2015a, p. 2). Precisamente, la regresividad del sistema tributario colombiano no asegura ni preserva el equilibrio del artículo 363 de la Constitución Nacional, contemplado para los principios tributarios, básicamente en razón de los numerosos descuentos, deducciones, exenciones, exclusiones en materia

2 El coeficiente Gini es un indicador que sirve para medir la concentración o distribución del ingreso en proporción a la población. El indicador se mueve entre cero y uno. Cuando está cercano a cero la concentración es muy baja y si está cercana a uno, la concentración es muy alta. 
de tributos, que no permiten modificar los efectos regresivos de dicho sistema. El exdirector de la Dirección de Impuestos y Aduanas Nacionales (DIAN), Horacio Ayala, advertía en su momento que "de acuerdo con el Banco Mundial, en 2010 había 99 beneficios tributarios en el impuesto de renta, con costo fiscal de 2,4\% del PIB; en diez años habían crecido $50 \%$ en número y $77 \%$ en el costo fiscal" (Acosta, 2018). Aunque esta expresión tiene un enfoque analítico de costo fiscal, no de regresividad, los beneficios presentaron costos fiscales y regresivos significativos, además de ser protegidos por la Ley 963 de 2005 a través de contratos de estabilidad jurídica.

Sin duda, cuando se sustraen los beneficios la tarifa efectiva que pagan las empresas es claramente menor que la tarifa nominal. De allí que no sea aceptable la opinión común según la cual en Colombia las empresas tributan hasta $70 \%$ sobre sus utilidades operacionales, lo cual explicaría su baja competitividad frente a otras empresas. Fedesarrollo ha señalado que la tasa efectiva es de solo el 29,5\%, ello, en sentido "progresivo" después del desmonte del impuesto sobre la riqueza y de la sobretasa al impuesto de renta, "amén de la supresión del impuesto a las remesas de utilidades, pasando la tasa nominal de $40 \%$ al 33\% en 2017" (Acosta, 2018). Al mismo tiempo, se habían desmontado los aportes parafiscales y la contribución del $20 \%$ en la tarifa de los servicios públicos. En relación con ello, es de resaltar la conclusión del citado estudio de los economistas del Banco de la República, según el cual "durante el periodo 1994-2016 las tasas efectivas promedio netas sobre el consumo, el trabajo y el capital fueron, respectivamente de 10,7\%, 18,6\% y $15,4 \%$; entre tanto para 2016, alcanzaron, en su orden, niveles de $11,2 \%, 20,8 \%$ y 21,4\%" (Acosta, 2018).

Por consiguiente, aunque la presión fiscal en Colombia del $14 \%$ del producto interno bruto (PIB) está por debajo del promedio de Latinoamérica, que oscila entre 16 y $17 \%$, la regresividad es mayor, en parte, debido a la erosión de la base impositiva a consecuencia de tales beneficios, que no son otra cosa que distorsiones en la equidad del sistema. A ello se suma el aspecto fiscal de la "alta tasa de evasión, calculada por la DIAN en $23 \%$ y por el FMI en $40 \%$, solo en lo que respecta al IVA, lo cual se cifra en \$14 billones, aproximadamente y de contera, la elusión fiscal" (Acosta, 2018). De ese modo, si bien en Colombia se aprueban numerosas reformas tributarias para aumentar los gravámenes, ello no redunda en mayores ingresos para el fisco ni en más redistribución, motivo por el cual seguimos siendo uno de los países con mayor desigualdad de ingresos en el mundo, no habiendo reforma alguna que en proyecto pretenda corregir los particulares excesos del Estatuto Tributario. En vez de apoyar este la carga tributaria en la capacidad contributiva, dando una mejor regulación en materia de tarifas y renovar el equilibrio del sistema, el estatuto lo hace sobre impuestos que afectan la renta de personas naturales con bajos ingresos desatendiendo así los principios del sistema.

Esto que se afirma supone algún grado de inconformidad con los patrones distributivos de la renta en el país desde el sistema tributario, para no señalar la desconfianza en la gestión pública en la misión de corregir esa falla económica. Realmente, la progresividad del sistema en términos de bienestar social, más que en procedimientos sancionatorios para 
aumentar el recaudo y gasto público, se encuentra en la aplicación de los principios constitucionales del sistema tributario. En otros términos, el sistema tributario no ha logrado dar aplicación a dichos principios debido a los beneficios tributarios excesivos, convertidos en un factor de regresividad.

Es de anotar que para el investigador los problemas históricos de por qué un sistema tributario marca una tendencia regresiva para mayor concentración del ingreso es una preocupación fundamental frente a los crecientes interrogantes hechos al funcionamiento de la economía en el país. Sin embargo, este escrito no busca tratar problemas históricos sobre la tendencia regresiva que sigue marcando el sistema tributario colombiano, tan solo centra su reflexión en el impuesto sobre la renta y el impacto fiscal que tienen los beneficios a la luz de los principios constitucionales del sistema tributario. El propósito no es otro que señalar la necesidad de moderar los beneficios tributarios en el impuesto sobre la renta ya que estos se han convertido en un factor de regresividad. Por ello, el artículo está dividido en dos partes: primero, hace una presentación resumida de los principios constitucionales para la determinación de un sistema tributario equitativo; precisamente, esta es una alternativa por la que han optado algunos países desarrollados como Noruega, Suecia, Dinamarca, quienes para corregir la inequidad vieron necesario mayor participación del Estado, cuyas economías crecen y sus ciudadanos tributan de manera progresiva, es decir, los que tienen mayores ingresos pagan más y los que tienen menos, menos; segundo, alude de manera resumida a ciertos beneficios tributarios en la renta (rentas exentas, descuentos tributarios, contratos de estabilidad jurídica, zonas francas, amnistías) que desde el punto de vista normativo tienen un impacto fiscal significativo, esto, por cuanto es también un modo de regresividad.

\section{Equidad, eficiencia y progresividad del sistema tributario}

\section{A. Aspectos generales sobre los principios constitucionales del sistema tributario}

El artículo 363 de la Constitución de 1991 establece que el sistema tributario se fundamenta en los principios de equidad, eficiencia y progresividad. Sobre la equidad tributaria, la Corte Constitucional ha considerado que esta actúa como límite a la potestad tributaria o impositiva que ostenta el legislador para la creación de gravámenes la cual deriva, a su vez, de la máxima según la cual no hay tributo sin representación. En virtud del carácter democrático del sistema constitucional colombiano, solo los organismos de representación popular podrán imponer tributos (Sentencia C-891/12). En general, la equidad tributaria refiere a la prohibición al orden jurídico de imponer obligaciones excesivas o beneficios excedidos al contribuyente. En términos de la jurisprudencia, la equidad tributaria es:

... un criterio con base en el cual se pondera la distribución de las cargas y de los beneficios o la imposición de gravámenes entre los contribuyentes para evitar que haya 
cargas excesivas o beneficios exagerados. Una carga es excesiva o un beneficio es exagerado cuando no consulta la capacidad económica de los sujetos pasivos en razón a la naturaleza y fines del impuesto en cuestión. (Sentencia C-734/02)

Según lo enunciado, el principio de equidad tiene diversas connotaciones, pero con especial predicamento en la manifestación del derecho fundamental de igualdad y fundamento mismo de la prohibición constitucional de los impuestos confiscatorios. Por eso, ha precisado la Corte Constitucional que la equidad "proscribe formulaciones legales que establezcan tratamientos tributarios diferenciados injustificados tanto por desconocer el mandato de igual regulación legal cuando no hay razones para un tratamiento desigual, como por desconocer el mandato de regulación diferenciada cuando no hay razones para un tratamiento igual" (Sentencia C-397/11). Así, en razón de la capacidad económica de los sujetos pasivos prohíbe que el orden jurídico imponga obligaciones excesivas o aplique beneficios excedidos, por un lado, porque se desprotege patrimonialmente a otros contribuyentes; por otro, porque no garantiza al Estado cumplir sus fines sitiando su fuente principal de recursos.

El principio tributario de progresividad, por su parte, pretende compensar la insuficiencia del principio de proporcionalidad en el sistema tributario pues en este ámbito no basta con mantener en todos los niveles una relación simplemente porcentual entre la capacidad económica del contribuyente y el monto de los impuestos a su cargo. Esta deficiencia la ha superado el legislador, según juzga la jurisprudencia constitucional, disponiendo que quienes tienen mayor patrimonio y perciben mayores ingresos aporten en mayor proporción al financiamiento de los gastos del Estado, es decir, para quienes tengan mayores ingresos y patrimonio, naturalmente, la carga tributaria sea mayor (Sentencia C-1003/04). Sin embargo, en un sentido amplio, la progresividad es la capacidad de un tributo para lograr como fruto de su aplicación una redistribución del ingreso que promueva la equidad (DIAN, 2006b, p. 8).

Ambos principios, según puede verse, constituyen parámetros para determinar la legitimidad y el equilibrio del sistema tributario, por lo que, sin lugar a dudas, se han de predicar del sistema en su conjunto y no de un impuesto en particular (Sentencia C-397/11). Para ilustrar esto, la jurisprudencia constitucional ha identificado, sin tener carácter taxativo, algunos supuestos que configuran vulneraciones al principio de equidad tributaria por tratarse de cargas excesivas o beneficios exagerados ${ }^{3}$. Algunos de estos son:

- El supuesto según el cual el monto que se debe pagar por concepto de tributo se define sin atender a la capacidad de pago del contribuyente. Por ejemplo, caso conocido y analizado en la sentencia C-876 de 2002, donde la jurisprudencia declaró inexequible la norma que establecía una base gravable presunta con carácter no desvirtuable, que incluso podía llegar a ser superior a la capacidad de pago del contribuyente. 
- El supuesto que resulta cuando la regulación grava de manera disímil a sujetos o situaciones jurídicas análogas, sin que concurra una justificación constitucionalmente razonable para ello. Caso puntual, el tratado en la Sentencia C-748 de 2009, donde la jurisprudencia constitucional concluye que se vulnera el principio de equidad al otorgarse beneficios tributarios a los magistrados del tribunal, con exclusión de otros funcionarios judiciales que históricamente habían recibido el mismo tratamiento legal, tanto de índole laboral, como administrativa y tributaria.

- La inobservancia del principio de equidad cuando el tributo es o tiene implicaciones confiscatorias. Ello, en el caso que la obligación fiscal implique una expropiación de facto de la propiedad privada o de los beneficios de la iniciativa económica de los particulares (Sentencia C-619/14). Esto en razón de que dicha actividad productiva deba destinarse exclusivamente al pago del tributo, impidiéndose el logro de ganancia para el sujeto pasivo del mismo. Así, el efecto confiscatorio opera cuando el impuesto genera un impacto desproporcionado en el patrimonio del contribuyente (Sentencias C-409/96; C-1003/04).

- El supuesto, con un carácter más general, que consiste en la prescripción por el legislador de tratamientos jurídicos irrazonables, bien porque la obligación fiscal se base en criterios abiertamente inequitativos o infundados, bien porque privilegian al contribuyente moroso en perjuicio de quienes cumplieron oportunamente con el deber constitucional de concurrir con el financiamiento de los gastos del Estado.

Los ejemplos anteriores muestran, de cierto modo, la necesidad que tiene el sistema tributario colombiano de incorporar las exigencias constitucionales de equidad y progresividad, además de buscar la eficiencia, esto es, asegurar un efectivo control de la recaudación de los dineros públicos y garantizar la protección a los contribuyentes del poder impositivo. Como se sabe, la eficiencia constituye un componente medular de justicia tributaria dado que la ineficiencia en el recaudo de los tributos puede generar una injusta distribución de la carga fiscal, en tanto el incumplimiento de las obligaciones impositivas por parte de algunos contribuyentes puede conducir a que el sostenimiento de los gastos e inversiones públicas solo se haga a costa de los contribuyentes cumplidos. Por ese motivo, lo que se pretende garantizar con el orden jurídico constitucional a través de los principios de equidad, eficiencia y progresividad es un equilibrio económico del sistema tributario, que lo haga progresivo en la redistribución del ingreso a fin de evitar la concentración de la riqueza, equitativo en la distribución de las cargas y eficiente en la protección de los contribuyentes.

\section{LA EQUIDAD COMO ANÁLISIS DE PROGRESIVIDAD DEL TRIBUTO}

Ha quedado esbozado que el principio tributario de equidad es la manifestación del derecho fundamental de igualdad y que la vulneración de este principio puede configurarse en una situación inequitativa, en varios sentidos: primero, cuando se grava de manera disímil 
a sujetos o situaciones jurídicas análogas; segundo, cuando se conceden sustanciales beneficios al deudor del tributo; tercero, cuando las cargas de distribución o imposición de gravámenes no tienen presente la capacidad contributiva del sujeto pasivo. Por consiguiente, es menester esbozar las razones explícitas por las que el principio de equidad se auxilia en el juicio de igualdad, cuyo propósito básico es determinar si una medida impositiva o la consagración de un beneficio cumple o no con la obligación de consultar la capacidad económica del sujeto pasivo o dar el mismo trato a supuestos de hecho equivalentes o a destinatarios que están en circunstancias similares.

Lo primero que se debe advertir es que la equidad y la igualdad no son principios idénticos; los cargos por violación del principio de igualdad tienen exigencias específicas que no tienen los cargos por violación de la equidad y viceversa. La equidad tributaria, como se indicó, se refiere al criterio con base en el cual se pondera la distribución de cargas y beneficios entre los contribuyentes, cuya finalidad es evitar la imposición excesiva de gravámenes tanto en sus cargas como en sus beneficios (Sentencia C-734/02).

En la Sentencia C-169 de 2014, la jurisprudencia enunció dos aspectos importantes que se pueden tomar como metodología de análisis del principio, pues, contienen varios elementos por considerar para resolver un cargo de inequidad tributaria. Allí se estimó que la violación de dicho principio puede presentarse en dos sentidos: cuando el monto que se va a pagar por concepto del tributo no se define atendiendo a la capacidad de pago del contribuyente; o, cuando se regula un tributo en virtud del cual dos sujetos o grupos de sujetos en iguales condiciones resultan gravados de manera desigual. Ambos aspectos señalan un camino al parecer distinto para el análisis de progresividad de un tributo, de donde se sigue que la equidad puede servir como criterio básico para determinar si existe regresividad por causa del sistema tributario, cuya aplicación origina concentración de la renta o, progresividad, cuando de su aplicación se originan beneficios en la distribución de la renta reduciendo la desigualdad. Para ampliar esto, la jurisprudencia constitucional ha enunciado en numerosas sentencias que el principio de equidad tiene doble dimensión, una vertical y otra horizontal (Sentencias C-743/15; C-668/15; C-056/19). Pero antes de tratar esta ordenación que responde al grupo de sujetos que se encuentran en condiciones iguales y que resultan gravados de manera desigual, conviene aludir al supuesto material de la capacidad económica por ser esta la medida general de la igualdad y criterio básico de la equidad vertical.

\section{a. La capacidad contributiva como medida general de la igualdad}

La capacidad económica no se consagró expresamente como principio en la parte sustancial del sistema tributario colombiano, sino que ha sido derivado en sentido material por vía jurisprudencial de preceptos constitucionales como la progresividad, la no confiscación y el deber de contribuir con arreglo a los principios de equidad y de justicia ${ }^{4}$. Sin 
embargo, la importancia que tiene consultar la capacidad económica en razón de la naturaleza y los fines del impuesto en cuestión, se debe a que se puede alterar el equilibrio que debe guardar el sistema tributario gravando de manera disímil sujetos o situaciones jurídicas análogas. Es ahí donde adquiere sentido la equidad tributaria como criterio base con el cual se ponderan la distribución de las cargas, los beneficios o la imposición de gravámenes entre los contribuyentes. Por este motivo, es preciso revisar la capacidad contributiva como riqueza efectiva y distinguirla de la capacidad económica como mera riqueza potencial.

\section{b. La capacidad contributiva como riqueza efectiva}

La capacidad contributiva como riqueza efectiva es el presupuesto o la fuente material de la tributación exigida por los principios de justicia y equidad. Esto quiere decir que si el flujo de ingresos no llega a configurarse, no se plasma el hecho imponible y el respectivo sujeto pasivo no se encuentra en la obligación de hacer el aporte. Así, la capacidad contributiva solo opera con base en la efectiva riqueza del sujeto obligado, lo cual indica que no cabe la probable ausencia de la correlación entre riqueza y tributación. Por ello es comprensible que la jurisprudencia haya indicado con insistencia que el deber de solidaridad que corre a cargo de cada miembro de la comunidad sirve de sustento a todo género de tributación (Sentencia C-333/93).

Aunque no sea del todo cierto que el deber de solidaridad sirva de sustento a cualquier género de tributación, el supuesto al cual se supedita necesariamente este deber es la efectiva idoneidad objetiva del sujeto presuntamente obligado por la norma tributaria para concurrir con su esfuerzo tributario a soportar y financiar las cargas públicas. Eso indica que la capacidad económica no es un axioma que pueda extraerse por simple deducción lógica, sino, como insistentemente ha señalado la jurisprudencia constitucional, "debe existir una correlación entre la imposición y un índice así sea mínimo de riqueza o de capacidad económica del sujeto obligado" (Sentencia C-333/93). En ese orden de ideas, la Corte Constitucional supone que carece de capacidad contributiva la persona cuyo nivel de ingresos se agota en la mera satisfacción de sus necesidades vitales mínimas.

Por consiguiente, la base de una efectiva capacidad contributiva, cuyo índice objetivo viene dado por el flujo de ingresos brutos percibidos, obliga a precisar si la capacidad contributiva del sujeto pasivo de un tributo, desde la perspectiva de la equidad fiscal, es un factor que puede limitar la facultad impositiva del Estado tanto para crear un gravamen como para exigirlo. Sin embargo, la virtualidad del principio material de capacidad económica en el ordenamiento tributario colombiano no ha conseguido precisar bien la distinción dentro de los mismos impuestos, sobre todo cuando es más exigente en unos (directos) que en otros (indirectos), ni ha logrado hacer una revisión exhaustiva de los efectos confiscatorios del tributo no solo en los casos de renta inexistente, sino también cuando se pretende gravar la riqueza potencial del sujeto. Esto debe mirarse hasta en la aplicación e interpretación de los tributos y enjuiciar la idoneidad del sujeto para el 
cumplimiento de la obligación tributaria según su particular capacidad económica, pues, allí es posible encontrar figuras tributarias que, lejos de gravar la verdadera riqueza, hagan tributar a sujetos por una riqueza inexistente, desconociendo con ello la justicia tributaria y el equilibrio deseado en el sistema. Por eso, se entiende que el criterio de tributación con arreglo a la capacidad contributiva constituye el núcleo central de los principios del sistema tributario, es decir, porque supone la igualdad en materia tributaria, siendo la progresividad y la no confiscación su consecuencia lógica.

La progresividad viene a ser, entonces, la aspiración de conseguir la igualdad material a través de la redistribución de la renta, en tanto que la no confiscación constituye un límite a la progresividad que impide agotar la capacidad económica. Por esta razón, se piensa que "la carga tributaria toma una importancia relevante y por ello, la capacidad económica como principio esencial en la distribución de la carga tributaria toma el adjetivo de capacidad contributiva" (Piza Rodríguez, 2003, p. 63). De acuerdo con esto, entiende Julio Roberto Piza que la capacidad contributiva tendría dos sentidos: primero, como criterio material de justicia tributaria; segundo, como medida de imposición individual. Naturalmente, los postulados clásicos para determinar la carga tributaria han sido el principio del beneficio y el principio de capacidad económica, este último como sucedáneo de la solidaridad social. No obstante, en razón de la justicia tributaria, es preciso utilizar como criterio de distribución de la carga tributaria la capacidad económica, en virtud del principio de solidaridad que subyace en el sistema impositivo (p. 63).

Sobre esto conviene anotar que, si bien los principios constituyen una condición de justicia formal, la justicia material exige no solo principios sino criterios para lograr una imposición igualitaria y socialmente justa. Esto ha derivado en que la capacidad económica no sea reconocida como un principio autónomo, sino más bien como un principio subsidiario de la igualdad o una expresión de igualdad relacionada con la equidad vertical o la progresividad. Justamente, ese es el motivo por el que el análisis puede resultar complejo, pues, en tanto que se predica del sistema y no de un impuesto en particular, resulta difícil elaborar un análisis simplemente jurídico del mismo, sobre todo cuando puede indicarse que la capacidad económica constituye un concepto jurídico indeterminado cuyo núcleo corresponde a la riqueza disponible.

Julio Roberto Piza señaló que, históricamente, el primer criterio que se utilizó como indicador de capacidad fue la riqueza entendida como patrimonio o bienes poseídos; luego, por las ventas e importaciones, es decir, las transacciones en sí mismas; subsiguientemente, la renta; posteriormente, el consumo. En ese sentido, la estructura tributaria combina a su criterio los tres indicadores de capacidad, a saber: la riqueza, con tarifas bajas o rentas presuntivas; la renta, como indicador de las utilidades personales y corporativas; y, el consumo, de manera más generalizada, gravando todo tipo de bienes y servicios (2003, p. 67).

Ahora bien, dejando de lado el aspecto material y pasando ahora a la capacidad económica como medida de imposición individual, se trata de establecer que la base gravable admita la depuración según el principio del neto objetivo, que para muchos doctrinantes mide de manera más justa la verdadera capacidad económica, vale decir, que se reconozcan 
los gastos necesarios para la subsistencia (Piza Rodríguez, 2003, p. 67). Ello responde al concepto de la renta neta como sinónimo de riqueza disponible, en su doble vertiente de ingresos y gastos. A esto habría que añadir un aspecto necesario como es corregir los efectos de la inflación que produce incrementos patrimoniales, rendimientos nominales de capital y efectos sobre la base y sobre la tarifa. En ese sentido, la medida de imposición individual "no se refiere únicamente a la capacidad productiva sino a la obtenida efectivamente, por lo cual se proscribe las presunciones y los rendimientos nominales, mediante los que se determina la intensidad del gravamen" (p. 68).

Por tanto, si definimos la capacidad económica como la riqueza disponible de un sujeto, esto indicaría que solo se debe exigir la renta neta, es decir, la riqueza efectiva o real, lo demás serían rendimientos ficticios o nominales. Sin embargo, el principio de capacidad económica queda ensombrecido aquí por cierta ambigüedad cuando se tienen en cuenta los beneficios excesivos que se convierten en reales distorsiones de la equidad. Esta visión de los beneficios ha llevado a aceptar demasiados privilegios, primordialmente, los tributos que se usan para fines que no son estrictamente recaudatorios, como una licencia para omitir la capacidad económica en función de fines extrafiscales, focalizar la inversión pública en un sector económico o en una zona geográfica, o en los casos de regímenes simplificados mediante normas que alteran la carga y que constituyen excepciones al principio de capacidad económica (Piza Rodríguez, 2003, pp. 74-75). En estos casos, la capacidad económica no es el referente impositivo.

Por estos motivos, además de las distorsiones que genera en la distribución de la carga tributaria y las posibilidades de elusión que fomentan estos mecanismos de difícil control, es que la utilidad de instrumentos tributarios ha sido muy cuestionada por sus resultados. De ahí que sea todavía discutible el elemento de la igualdad como guía del sistema tributario cuando se trata de otorgar un tratamiento distinto a supuestos semejantes o que manifiesten la misma capacidad económica, pues, en estos casos, realmente no estamos ante unas cargas reales, si se toman en consideración una cantidad de beneficios y la idea que mantiene sobre la capacidad, luego de aplicar los mismos. Esta lógica no asegura por sí sola un sistema tributario justo inspirado en los principios de igualdad y progresividad.

Así las cosas, y sin el ánimo de dejar de pensar en la función social de la propiedad -que es donde radica el impulso de la distribución de la riqueza-, el sistema tributario se ha considerado más como un mecanismo para frenar el impulso distributivo, pensándose mayormente con lógica civil y comercial, que con lógica constitucional ${ }^{5}$. Ello es motivo

5 El artículo 58 de la Constitución Nacional señala que se garantiza la propiedad privada. Sin embargo, el mismo artículo advierte que el interés privado deberá ceder al interés público o social. En otras palabras, la propiedad no se fundamenta en una libertad absoluta, sino que se restringen las libertades individuales de las personas, entre ellas, el derecho a la propiedad privada, en aras de lograr la conservación o preservación del medio ambiente, el interés social o el urbanismo, que constituye también interés público y social. Esto permite exponer un cuadro más completo de la libertad y la capacidad económica, señalando que el ordenamiento se fundamenta en "la función social y ecológica de la propiedad, la prevalencia del interés general sobre el particular y la distribución equitativa de las cargas y los beneficios" (Sentencia C-192/16). Con esto, se resalta que no solo se ha de limitar el alcance del derecho de propiedad frente al uso del suelo, sino que también los beneficios tributarios, que 
para advertir que la función social y ecológica de la propiedad no puede ser una causa para justificar cargas excesivas, pero tampoco la libertad económica para establecer beneficios excesivos.

\section{c. La capacidad económica como mera riqueza potencial}

El principio de capacidad económica opera como límite al poder impositivo, no solo aplicado sobre la riqueza real, sino también y con mayor razón sobre la potencial. Ejemplo de ello son las disposiciones del impuesto al patrimonio y sus variaciones, cuando pesan sobre estos aspectos externos que reducen el poder adquisitivo. En estos casos, estaríamos frente a situaciones donde el gravamen recae sobre una riqueza inexistente, que sería un poco similar a los casos donde no se consulta la capacidad económica, como algunas veces en el IVA. De ese modo, se hablaría prácticamente de capacidad económica virtual o ficticia, que equivale a renta potencial y, por eso, sin anclaje constitucional. Razón por la cual no le asiste autoridad al legislador gravar riquezas meramente virtuales, ficticias o inexpresivas. En dicha instancia sería ilegítimo el uso de instrumentos fiscales cuando la riqueza es potencial, puesto que sería un contrasentido constitucional decir que no se puede gravar si no se consulta la capacidad económica y que se grave la capacidad económica potencial.

Por tanto, aunque existen muchas manifestaciones de capacidad económica, solo hay una fuente impositiva que es la riqueza que se obtiene y que se ha acumulado, de modo que los impuestos deben corresponder a esa capacidad económica. La renta, en primer lugar, como indicador por excelencia; en segundo lugar y de modo subsidiario, la riqueza y el consumo de ciertos bienes, en tanto constituyen usos de la renta. En los casos de consumo, ha indicado con insistencia la doctrina que en el IVA

... el uso de tarifas diferenciales introduce tal complejidad a la administración que se ha optado por utilizar más bien tarifas generales, que por supuesto comportan una característica regresiva, que se ha mitigado, excluyendo bienes de primera necesidad y gravando bienes suntuarios, como una manifestación de la tributación en virtud de la capacidad económica. (Piza Rodríguez, 2003, p. 69)

Para ampliar un poco dicho aspecto, Julio Roberto Piza señaló que también se han invocado en la jurisprudencia, tanto la solidaridad como la función social de la propiedad, como elementos que subyacen en la fuente de la capacidad económica (2003, p. 71). No obstante, también admite la jurisprudencia el mínimo exento, esto es, los activos como el

generan precisamente una distorsión de la función social y ecológica de la propiedad, puesto que promueven un imaginario social de una propiedad sin límites. Siendo así, los beneficios terminarían otorgándole primacía a la propiedad sobre el interés general, lo que afecta no solo su función, en sentido amplio, desde la distribución inequitativa de las cargas en materia de tributos. Por tanto, si la política fiscal busca la equidad, esta no se construye con base en un tributo en particular para la equidad, sino desde el sistema mismo. 
patrimonio (Sentencia C-333/93) y los ingresos brutos (Sentencia C-252/97), como indicadores adecuados para medir la capacidad económica, sin olvidar que también existen otros indicadores indirectos de riqueza idóneos para determinarla. En relación con las tarifas, Julio Roberto Piza consideró que, si bien la progresividad recoge mejor este principio, también son idóneas las tarifas diferenciales tratadas por la jurisprudencia en las sentencias C-103 y C-144 de 1993, como las tarifas proporcionales (2003, p. 71).

Para efectos fiscales, en las sentencias citadas se distingue el patrimonio bruto del patrimonio líquido; al primero habrá que restarle el monto de las deudas a cargo de este, vigentes en esa fecha, para obtener el patrimonio líquido que es sobre el que recae el cobro del impuesto. Claro está, subsisten impuestos sobre patrimonio bruto, como el impuesto predial, o sobre ingresos brutos, como el impuesto de industria y comercio. De hecho, para mitigar su efecto sobre la capacidad neta, se utilizan tarifas bajas, lo cual implica que la medición es más imperfecta (Piza Rodríguez, 2003, p. 71). Esto suscita cierta inquietud ya que para algunos autores los conceptos de patrimonio neto y renta neta son más equitativos porque a su juicio miden mejor la capacidad contributiva que los conceptos de patrimonio y renta bruta. Ello es tanto más cierto, porque el costo de mayor equidad torna complejo el impuesto y aumenta el control, lo que da lugar a nuevas fuentes de inequidad por razones de elusión y evasión, que se agravan por las limitaciones de control (p. 71).

Con todo, se ha de valorar la tributación teniendo en cuenta la capacidad económica que muestren los sujetos pasivos del impuesto, es decir, entendiendo la capacidad como medida de igualdad. Este principio, así pensado, no exige que el legislador haya de dar un trato igualitario o no a los rendimientos de distinta naturaleza obtenidos por un contribuyente. De hecho, el legislador puede someter a distintos tipos de gravámenes las rentas regulares e irregulares. Con ello se quiere anotar que no es constitucionalmente válido hacer soportar una mayor tributación a quienes perciben rentas cuya parte imponible es menor, por no alcanzar los rendimientos mínimos sometidos a tributación, pues ello demostraría desigualdad ante la ley. En ese sentido, el presupuesto no puede ser otro, quienes tienen menor capacidad económica soportan una mayor carga tributaria que los que tienen una capacidad superior. En esa medida, la capacidad económica debería tener cierto control de proporcionalidad, como la deducción variable para corregir los efectos de la acumulación de rentas.

Así las cosas, y como criterio general de la igualdad, la riqueza efectiva como base gravable del impuesto sobre la renta y complementarios no será, en el primer caso, la magnitud o el valor de la renta líquida gravable ni, en el segundo, la magnitud o el valor de la renta presuntiva, obtenida esta última a partir del patrimonio bruto o del patrimonio líquido, según el caso. Será simplemente la que se cause de acuerdo con los fines fiscales en equidad. Esto, porque si bien técnicamente la igualdad puede lograrse mediante deducciones, descuentos o tarifas, también subyacen ciertas injusticias con quienes son objeto de privilegios fiscales y para quienes se encuentran por debajo del mínimo no gravado. En todas estas indicaciones no se puede encontrar la capacidad contributiva como medida general de la igualdad, por eso, se ha de mirar desde la equidad misma sus dimensiones a 
fin de encontrar las exigencias constitucionales de igualdad y progresividad en el sostenimiento de las cargas fiscales.

\section{B. Equidad vertical y equidad horizontal}

Como se indicó, la jurisprudencia ha diferenciado dos dimensiones de la equidad, la vertical y horizontal. La primera, identificada con la exigencia de progresividad, ordena distribuir la carga tributaria de manera tal que quienes tienen mayor capacidad económica soporten una mayor cuota de impuesto. Esto implica una mayor carga tributaria sobre aquellas personas que tienen más capacidad económica. La equidad horizontal, por su parte, considera que el sistema tributario debe tratar de idéntica manera a las personas que, antes de tributar, gozan de la misma capacidad económica, de modo tal que queden situadas en el mismo nivel después de pagar sus contribuciones (Sentencia C-169/14). Esto hace referencia a los sujetos pasivos que se encuentran en una misma situación fáctica, los cuales deben contribuir de manera equivalente.

Para hacer más explícita la anterior distinción, se podría decir que la capacidad que se expresa en la equidad vertical y en el principio de progresividad, por fundarse en el principio de solidaridad, cumple una finalidad redistributiva de las cargas en la sociedad, de acuerdo con tarifas diferenciales como en el impuesto directo. En cambio, en la equidad horizontal se trata de medir la propensión al consumo -como en los impuestos indirectosdado que, al parecer, no se modifica su misma situación fáctica. Con todo, en el consumo todavía no hay un criterio que permita verificar realmente quiénes tienen la misma capacidad de pago.

\section{a. La progresividad del impuesto de acuerdo con la equidad vertical}

Teniendo presente que el principio de progresividad tributaria dispone que los tributos han de gravar de igual manera a quienes tienen la misma capacidad de pago (equidad horizontal) y han de gravar en mayor proporción a quienes disponen de una mayor capacidad contributiva (equidad vertical), se puede comprender ahora en mayor medida lo considerado por la Corte Constitucional en la Sentencia C-397 de 2011, especialmente donde se refiere a la relación existente entre los principios de equidad y progresividad. Allí se lee:

... Existe concurrencia entre los principios de equidad y progresividad, ya que ambos aluden a la distribución de las cargas en el sistema tributario, así como a los beneficios que se establecen dentro del mismo, diferenciándose, sin embargo, en que el principio de equidad es un criterio más amplio e indeterminado de ponderación que atañe a la manera en que determinada disposición tributaria afecta a los diferentes destinatarios a la luz de los valores constitucionales, en tanto que el principio de progresividad atañe a la manera en que determinada carga o beneficio tributario modifica la situación económica de un grupo de personas en comparación con las demás. 
Aunque en los términos del artículo 363 de la Constitución, la equidad es un principio que informa el sistema tributario en su conjunto, su componente horizontal es eminentemente relacional y se funda en la comparación entre capacidades económicas de los sujetos pasivos del tributo. En cambio, el componente vertical guarda identidad de propósito con el principio de progresividad tributaria, el cual se predica no tanto de los contribuyentes individualmente considerados, sino del sistema impositivo en su conjunto. En ese sentido, la progresividad se ha de mirar como complemento de la equidad vertical, pero en tanto que la carga o el beneficio tributario modifique la situación económica de un grupo de personas en comparación con las demás. De ahí que pueda decirse que estas dos versiones se identifican, no obstante, con una compresión estructural e individual de la equidad tributaria.

Ahora bien, como era razonable, la Corte Constitucional no podía conferir un alcance absoluto al principio de progresividad de modo que se sacrificara la equidad y se pusiera, además, al Estado en la imposibilidad financiera de realizar sus objetivos (Sentencia C-333/93). Por eso, cuando la progresividad se refiere a la tarifa proporcional del tributo, esta se ha de pensar más que como criterio de eficiencia administrativa y recaudo del gravamen, como un factor acreditativo de capacidad económica en tanto tipo impositivo examinado y suficiente. La tarifa proporcional atiende al principio de equidad en cuanto trata de manera semejante a quienes se encuentran en una situación disímil para soportar la carga del tributo. Al no ser el gravamen el factor generador de desigualdad, mal puede imputársele efectos inequitativos pues se le estaría atribuyendo obedecer a una etiología diversa a otra causa fiscal. Ello no indica que el principio de progresividad se deba interpretar en el sentido de que todos los tipos impositivos deban ser "progresivos", pues, ello reduciría ostensiblemente la fuente legítima de imposición que aporta enormes recursos al fisco, lo que genera déficit fiscal, pero tampoco se deben impulsar las conocidas secuelas de evasión y elusión que son para la jurisprudencia las principales responsables de la inequidad en materia tributaria (Sentencia C-333/93).

Es importante observar, entonces, que los principios constitucionales especificados tienen capacidad conformadora de la realidad social de acuerdo con su interpretación o aplicación. El legislador debe, por ello, ponderar con sobriedad y precisión los principios a fin de que el sistema tributario los refleje adecuada y equilibradamente, sobre todo, si se considera que la reivindicación absoluta de uno de ellos pone en peligro los demás. La tarea no es sencilla, pero se debe hacer lo posible para que los principios coexistan en justicia y sus antagonismos se reduzcan al máximo dentro de lo razonable. La misma jurisprudencia comprende que no se puede conferir un alcance absoluto al principio de progresividad porque, como se anotó, se sacrificarían la equidad y la eficiencia, por lo que se terminaría poniendo en juego al Estado, que quedaría en imposibilidad financiera para realizar sus objetivos (Sentencia C-833/13).

En resumen, según el artículo 95, numeral 9 de la Constitución, todas las personas deben contribuir al financiamiento de los gastos e inversiones del Estado, pero esta 
contribución debe hacerse dentro de los principios constitucionales que constituyen parámetros o límites al ejercicio del poder tributario. El principio de equidad incorpora el mandato general de tributación de distribuir la carga tributaria entre todas las personas con capacidad de pago. La forma en que debe llevarse a cabo dicha distribución debe incluir, por un lado, el criterio de equidad horizontal para tratar de idéntica manera a las personas que, antes de tributar, gozan de la misma capacidad económica, de modo que queden situadas en el mismo nivel después de pagar sus contribuciones; por otro lado, debe incluir el mandato de equidad vertical, identificado con la exigencia de progresividad, que ordena distribuir la carga tributaria de manera tal que quienes tienen mayor capacidad económica soporten una mayor cuota de impuesto (Sentencia C-833/13). La eficiencia constituye un componente medular de la justicia tributaria dado que la ineficiencia en el recaudo de los tributos puede generar una injusta distribución de la carga fiscal, en tanto que el incumplimiento de las obligaciones por parte de algunos contribuyentes conduce a que el sostenimiento de los gastos e inversiones públicas solo se haga a costa de los contribuyentes cumplidos.

\section{La regresividad de los beneficios tributarios excesivos}

Colombia es una de las naciones más inequitativas de Latinoamérica en términos de ingresos (DIAN, 2016; Bautista, 2011; González y Corredor, 2016; Jiménez, 2015). Este hecho tiene, naturalmente, numerosas causas (económicas, políticas, sociales, históricas y jurídicas), que difícilmente podrían tratarse aquí en su conjunto, razón por la cual este trabajo solo se refiere de manera concisa a ciertos aspectos normativos que generan concentración de riqueza, en especial los beneficios tributarios que podrían calificarse como regresivos en materia fiscal, ya que los componentes progresivos del sistema tributario registran grandes falencias ${ }^{6}$. En ese sentido, no se pretende realizar un estudio de medición nacional o internacional del costo de los mismos, debido a que no se refiere de manera directa y detallada al costo fiscal de cada uno de los beneficios conforme a lo dispuesto en la Ley 819 de 2003, que obliga al Gobierno nacional a presentar un informe ante las comisiones económicas del Senado y Cámara, en un marco fiscal que contiene la estimación anual del costo fiscal de las exenciones, deducciones y descuentos tributarios (art. 1, lit. f).

Es de anotar que la medición adoptada sobre estos beneficios corresponde a un cálculo que estima la pérdida de recaudo que se produce después de la entrada en vigencia de la norma que brinda algún beneficio. Su fuente de información es extraída de los registros

6 La regresividad fiscal es una forma de clasificar los impuestos, según su relación con el ingreso del contribuyente. Un impuesto progresivo es aquel cuya tarifa de tributación aumenta en la medida en que el ingreso aumenta, mientras que un impuesto regresivo es aquel en el que la tarifa de tributación es menor en la medida en que el ingreso aumenta. A la luz de la jurisprudencia un impuesto es regresivo "a medida que aumenta la capacidad de pago del contribuyente, disminuye la tarifa del impuesto a pagar", mientras que un impuesto progresivo es aquel que "a medida que aumenta la capacidad de pago del contribuyente, aumenta la tarifa del impuesto a pagar" (Sentencia C-100/14). 
administrativos de las declaraciones tributarias presentadas por los obligados en los dos últimos años gravables, de acuerdo con el monto de sus ingresos o patrimonio. El análisis de la información se realiza por subsector económico, por tipo de declarante y por el tipo de contribuyente (DIAN, 2018, p. 8). De tal manera, que el Marco Fiscal de Mediano Plazo debe reflejar un ajuste que garantice la sostenibilidad de la deuda pública. Por ese motivo, se puede decir que es una medición enfocada más en la compatibilidad de los beneficios tributarios con el Marco Fiscal de Mediano Plazo, que enfocada en un marco constitucional que dé cuenta de los principios que equilibran el sistema tributario.

Además de los beneficios en el impuesto sobre la renta -esto es, los ingresos no constitutivos de renta ni ganancia ocasional, las deducciones, los descuentos tributarios y las rentas exentas-, otro que ilustra bien la regresividad del sistema es el impuesto al valor agregado (IVA), cuando grava el consumo de bienes y servicios de vital necesidad prescindiendo de la capacidad contributiva del sujeto pasivo. Este impuesto, así aplicado, muestra de igual modo que muchos programas -como los subsidios- resultan inoperantes cuando se vuelven a quitar a las familias de bajos recursos vía impuestos al consumo. Algunos autores han explicado esto de la siguiente forma: si un hogar con bajos ingresos recibe subsidios a través de un programa, es factible que al pagar impuestos como el IVA revierta al Estado una cantidad igual o mayor que el monto de sus subsidios. Si la visión estructural corresponde al balance entre impuestos y subsidios, el ingreso disponible sería la mejor expresión de esta relación. Sin embargo, según advierten estos autores, el resultado estructural se refleja en el ingreso disponible (González y Corredor, 2016).

Con base en el anterior razonamiento se puede advertir que las evaluaciones de la política fiscal y, en particular, el balance del costo fiscal conforme a lo dispuesto en la Ley 819 de 2003, no se realizan observando otros aspectos como el conjunto de la relación entre la evolución de los subsidios y los impuestos. Además, si bien es notorio que existen muchos otros factores que afectan la progresividad, para la mayoría de los hogares colombianos el caso del IVA no constituye un mecanismo efectivo para mitigar la concentración del ingreso en puntos significativos del índice Gini. De allí que el sistema impositivo constituido por el IVA tenga efectos inoperantes en los términos descritos, sobre todo cuando la carga tributaria fija en gran medida el perfil progresivo/regresivo del sistema tributario.

Lo indicado tal vez podría generar una aparente objeción al señalar que desde el sistema tributario nacional el análisis no revela que exista realmente regresividad en un sistema representado por tributos como la renta o el IVA, pues, su aplicación no causa de manera ineludible un menoscabo en la concentración de la renta. Empero, pese a tratarse de un fenómeno multicausal, tampoco se puede afirmar de manera categórica que la tributación colombiana del orden nacional sea progresiva (DIAN, 2006, p. 7). De hecho, parte del fracaso de la gestión pública en la misión de corregir los patrones negativos de la distribución de la renta tiene cierto inicio en la disposición legislativa dada a los principios del sistema tributario ya que otorga, claramente, preferencia a los fines económicos sobre los principios constitucionales. 


\section{A. Aspectos regresivos de los beneficios tributarios en el impuesto sobre la renta}

El legislador colombiano ha buscado alcanzar objetivos económicos importantes para el país, a saber: el desarrollo de las regiones, la promoción de sectores económicos determinados, el desarrollo tecnológico, la generación de empleo, entre otros. Estos, ciertamente, aplicando beneficios tributarios (deducciones, descuentos, rentas exentas, tratamientos tributarios especiales y algunas tarifas diferenciales $)^{7}$, que representan para algunos contribuyentes una disminución notable en su obligación tributaria.

Sin valorar la certeza de estos objetivos, desde el año 2011 hasta 2016, los beneficios para las empresas estuvieron en promedio alrededor del 3,0\% como proporción del PIB (DIAN, 2018, p. 14). Según informa la DIAN, en el año gravable 2017 esta proporción se situó en 1,4\%, como producto de la eliminación de algunas rentas exentas establecidas en la Ley 1819 de 2016. En aquellos años, el costo fiscal varió de modo significativo: se ubicó en 0,7\% del PIB en el año 2017, mientras que en el año 2010 el costo fiscal representó $1,3 \%$ (p. 14). Lo característico para la DIAN es que desde el año 2010 el beneficio con mayor costo fiscal siguen siendo las rentas exentas, seguido de la deducción por inversión en activos fijos, los descuentos tributarios, el tratamiento tributario de tarifas diferenciales a usuarios de zonas francas y lo correspondiente a los contratos de estabilidad jurídica

7 Es importante resaltar que la Dian presentó una cuantificación de los beneficios tributarios en el impuesto sobre la renta durante el año gravable 2017 y su costo fiscal para las finanzas de la nación en 2018, donde describió la incidencia de estos. Para precisar, anotamos lo siguiente: "Las rentas exentas y los descuentos constituyen un beneficio tributario, pero no así el agregado de los ingresos no constitutivos de renta, como tampoco el total de deducciones. Precisamente, el proceso de depuración en las declaraciones del impuesto sobre la renta, está encaminado a establecer la base gravable del contribuyente. Sobre tal base se aplica la tarifa fijada por la ley obteniendo el impuesto básico que, a su vez, se afecta con descuentos tributarios, para llegar finalmente al impuesto neto a cargo del contribuyente. En el caso de los tratamientos preferenciales que afectan la base gravable, estos se reflejan en tres grandes rubros que intervienen en este proceso de depuración: los ingresos no constitutivos de renta, las deducciones y las rentas exentas.

Por otra parte, se encuentran los descuentos tributarios, que afectan directamente el monto del impuesto sobre la renta que se liquida. Los ingresos no constitutivos de renta corresponden a aquellos ingresos que no están sometidos al impuesto sobre la renta por expresa disposición legal, ya sea por las circunstancias en que se generan o porque el sistema tributario encuentra conveniente estimular alguna actividad de la economía.

Las deducciones también reducen la base gravable, pero solo un subconjunto de las mismas constituye beneficio tributario al estar asociadas con gastos que no guardan relación de causalidad con la generación de la renta. Es el caso de las inversiones en proyectos desarrollo tecnológico e innovación; en evaluación y exploración de recursos naturales no renovables, y algunas donaciones, entre otros.

Otra categoría de beneficios que afectan la base gravable del impuesto la integran varias rentas laborales exentas, entre ellas, indemnizaciones, cesantías y pensiones, así como la exención otorgada a los asalariados respecto de los pagos laborales que perciben.

Además de las exenciones laborales se pueden mencionar algunas rentas exentas generadas por: los servicios hoteleros, la venta de energía eléctrica generada con base en los recursos eólicos, biomasa o residuos agrícolas; las nuevas plantaciones forestales.

Finalmente, dentro de los beneficios, igualmente se hallan los descuentos tributarios, verbigracia, los impuestos pagados en el exterior, a las empresas de acueducto y alcantarillado y a las sociedades agropecuarias, y el IVA pagado en la importación de maquinaria pesada para industrias básicas" (DIAN, 2018, p. 16). 
(p. 14). Lo anterior, teniendo presente que con la expedición de la Ley 1430 de 2010, se eliminó la deducción por inversión en activos fijos reales productivos, lo cual significó un descenso representativo dentro de los beneficios otorgados a las empresas. Sin embargo, esta prerrogativa se mantuvo para las que años atrás habían firmado contratos de estabilidad jurídica con la nación a fin de mantener condiciones estables que favorecieran la inversión. Este aspecto indica que la cuantificación de los conceptos que se pueden catalogar plenamente como beneficio tributario, identificables en el formulario de declaración de impuesto, puede ser una figura propiamente regresiva (p. 16).

Como se mencionó, el costo fiscal se define como el ingreso que deja de percibir el Gobierno nacional por concepto de la utilización de cualquiera de los beneficios tributarios contemplados en la ley. El cálculo de dicho costo se establece según el valor del impuesto que se habría generado si el beneficio en cuestión hubiera hecho parte de la base gravable de los declarantes. En el caso de los beneficios tributarios, que afectan la base gravable de los declarantes en el impuesto sobre la renta, el costo fiscal se calcula como el producto obtenido entre el monto del beneficio solicitado y la tarifa del impuesto. Para las personas jurídicas, la tarifa general fue de $34 \%$ (año gravable 2017), con una sobretasa del $6 \%$ y, en el caso de las personas naturales, se determinó una tarifa implícita del 13,3\% (DIAN, 2018, p. 16). En cuanto a los descuentos tributarios (que afectan directamente el valor del impuesto por pagar), el costo fiscal del beneficio equivale al valor descontado.

Esta aproximación al costo fiscal en el impuesto sobre la renta, para efectos de análisis, debería presentarse según la clasificación de los beneficios por subsector económico. No obstante, en el caso de las personas jurídicas, la legislación utiliza un análisis que inicia con la información contenida en las declaraciones del impuesto sobre la renta para el año gravable en particular. Al resumir el valor y el costo fiscal de los principales beneficios tributarios en el impuesto sobre la renta en el año gravable 2016, frente a lo correspondiente a las personas jurídicas en el año gravable 2017, la DIAN señaló que

... el monto total de los beneficios tributarios para el total de declarantes por el año gravable 2016 ascendió a \$64.226 miles de millones $(\mathrm{mm})$ (7,4\% del PIB), generando un costo fiscal de $\$ 10.616 \mathrm{~mm}$ (1,2\% del PIB). De este costo, el 86,4\% (\$9.171 mm) correspondió a las rentas exentas; 6,9\% (\$728 mm) a los descuentos tributarios; y 6,7\% (\$716 mm) a la deducción por inversión en activos fijos. (DIAN, 2018,p. 18)

Por esto es conveniente hacer una revisión normativa sobre el resultado de la política de beneficios contemplada en la legislación, bien para que se procure un razonable desmonte, como ha venido ocurriendo ya con algunos beneficios, bien para que se procure la revisión de los términos en que se hace la medición del impacto fiscal procurando el análisis de la regresividad en la determinación del sistema tributario y no de un impuesto particular.

En principio, es importante considerar que los beneficios tributarios pueden acarrear tanto aspectos progresivos como regresivos. En el segundo caso, entrañan una forma de anular o aminorar la carga impositiva para los sujetos pasivos, lo que afecta la equidad 
horizontal que prohíbe romper el principio de igualdad para dispensar del cumplimiento de las obligaciones tributarias a un sujeto pasivo o grupo, sin que medien circunstancias que justifiquen un trato diferenciado. Justamente, esta exigencia, al igual que la equidad vertical, se ve depuesta ante un razonamiento constitucional cuando el legislador establece beneficios, amnistías u otros mecanismos de saneamiento tributario de modo excesivo (Sentencia C-833/13) ${ }^{8}$.

Conforme queda visto, el balance del impacto fiscal señalado en la Ley 819 de 2003, y más concretamente, el resultado de la política de beneficios tributarios concedidos en el impuesto sobre la renta de personas jurídicas y naturales con obligación de presentar declaración anual del tributo es indiscutiblemente reducido cuando es entendido solo como costo fiscal. Por eso, la postura de la DIAN advierte que la forma excesiva de los beneficios constituye un elemento distorsionante e inequitativo para la tributación (DIAN, 2018, p. 9). La solución hasta el momento prevista ha sido el desmonte de los beneficios tributarios por parte del gobierno en los años recientes, cuando el equilibrio podría lograrse desde su moderación.

A continuación, se resumen algunas conclusiones que se pueden extraer de la DIAN sobre estos aspectos particulares.

- Frente al costo fiscal observado en el año gravable 2013, se registró un incremento de $11,7 \%$ (\$701 mm), lo cual refleja el aumento en la utilización de las rentas exentas por parte de las personas jurídicas, así como de la deducción por inversión en activos fijos (DIAN, 2015a, p. 5).

- El costo fiscal de los principales beneficios tributarios en el impuesto sobre la renta en el año gravable 2014, teniendo en cuenta el monto total de los beneficios tributarios para el total de declarantes de dicho año gravable ascendió a $\$ 47.690$ miles de millones $(\mathrm{mm})(6,3 \%$ del PIB), generando un costo fiscal de $\$ 6.704 \mathrm{~mm}(0,9 \%$ del PIB). De este costo, el 73,5\% (\$4.926 mm) correspondió a las rentas exentas; 14,1\% (\$947 mm) a los descuentos tributarios, y 12,4\% (\$830 mm) a la deducción por inversión en activos fijos (DIAN, 2015a, p. 5).

- La existencia de los beneficios constituye un elemento distorsionante e inequitativo para la tributación, siendo el desmonte de los beneficios tributarios una de las tareas principales del gobierno en los años recientes. Por ejemplo, el descenso en el costo de los beneficios de las personas jurídicas, de 1,3\% del PIB en 2010 a 0,7\% del PIB en 2017, obedece principalmente a la eliminación de la deducción por inversión en

8 Es importante aclarar que no se menciona el costo fiscal en tanto ello sea indicador fiscal, solamente se señala con ocasión de la progresividad. De allí que solo mencionemos, a modo de inventario, los beneficios y su concepto sin atenernos a un análisis normativo exhaustivo. Los otros balances se pueden encontrar en trabajos de la DIAN en diferentes vigencias $(2014,2016,2018)$ y en informes que presenta el Gobierno nacional a las comisiones respectivas. Aunque un balance fiscal puede mostrar que ha mejorado el costo fiscal, la regresividad sigue intacta. De ahí que sea necesario mencionar tanto la equidad como la progresividad tributaria. 
activos fijos establecida en la Ley 1430 de 2010 para casi la totalidad de los declarantes (DIAN, 2018, p. 9).

- La filosofía detrás de la inclusión de nuevos declarantes en el sistema de declaración era imprimir mayor equidad a la estructura tributaria en tanto permitía la recuperación de las retenciones practicadas en exceso que antes el contribuyente, en su condición de no declarante, no podía solicitar a la administración tributaria (DIAN, 2018, p. 9).

- Las sociedades que utilizaron descuentos lograron reducir su impuesto básico de renta, en promedio, en 4,4\%. Otros contribuyentes pertenecientes a otras actividades de servicios, por ejemplo, suministro de electricidad, gas, vapor y aire acondicionado; actividades de servicios administrativos y de apoyo, redujeron su impuesto de renta en $18,3,12,3$ y $10,7 \%$, respectivamente (DIAN, 2018, p. 26).

- Si se discrimina entre los descuentos tributarios utilizados por el sector privado y el sector público/mixto, los primeros concentran el 72,8\% del total de los descuentos (\$561 mm). Asimismo, de los 19 subsectores que utilizaron los descuentos tributarios, cuatro subsectores concentran el 73,8\% (DIAN, 2018, p. 26).

- En el caso de las personas naturales, el uso de los beneficios se incrementó en una magnitud importante al pasar de 0,3\% del PIB en 2010 a 0,7\% del PIB en 2016. Este incremento no corresponde a la creación de nuevas exenciones para las personas naturales; por el contrario, estas se mantuvieron sin modificación durante el periodo de análisis. En realidad, se trata de la incorporación de nuevos declarantes del impuesto desde el año gravable 2013, a partir de la entrada en vigencia de la Ley 1607 de 2012, que bajó el límite de ingresos a partir del cual se declara el impuesto (DIAN, 2018,p. 9).

- El sistema tributario cumple con los principios de equidad y progresividad, según la DIAN, pues, al incorporarse nuevos declarantes en la base, también les reconoció los beneficios tributarios a estos, que en muchos casos implicaron una disminución en la obligación tributaria que seguramente antes no podían materializar. Aunque este no sería propiamente un argumento para ratificar que se cumpla con dichos principios, para la DIAN el principal beneficio tributario de las personas naturales lo constituyen las rentas exentas, entre las que se destacan las provenientes del $25 \%$ por pagos laborales, los aportes a las AFC, las pensiones voluntarias y obligatorias, las cesantías, las indemnizaciones, etc. Estos beneficios se constituyen en una carga importante al momento de la liquidación del impuesto a cargo de estos contribuyentes y, por ende, en lo que aportan a las rentas del Estado, es decir, la valoración de la renuncia tributaria en la que incurre el fisco como gasto extrapresupuesto, conocido como el costo fiscal de las rentas exentas (DIAN, 2018, p. 12).

\section{RENTAS EXENTAS}

Al revisar la evolución de las rentas exentas en el periodo 2010-2016, la DiAN observa que si bien en el año 2012, estas tenían una magnitud cercana a los $\$ 15,7$ billones de pesos, al año siguiente prácticamente se duplicaron al pasar a \$29,2 billones en el año gravable 
2013, y al final del periodo señalado se acercan a los $\$ 46,0$ billones, mostrando un crecimiento en la variable cercano al $57 \%$ entre 2013 y 2016 (DIAN, 2018, p. 12).

Dentro de la evolución de las rentas exentas de las personas jurídicas como porcentaje del PIB, se ha encontrado en años anteriores, por ejemplo, que entre los años gravables 2008 a 2010 el indicador aumentó gradualmente hasta situarse en 11,2\% en el último año, debido al crecimiento de las rentas exentas año tras año por encima de la variación de la renta líquida gravable. Según informa la DIAN, entre 2010 y 2011, las rentas exentas presentaron una variación de $15,3 \%$, por lo que estas representaron el $8,7 \%$ de la renta ampliada. Para los años gravables 2012 y 2013 se observa un crecimiento superior de las rentas exentas frente al incremento de la renta líquida gravable en cada uno de los dos años, por lo que el indicador se situó en 9,3\% en el año gravable 2012 en tanto que para el año gravable 2013 fue de 10,3\% (DIAN, 2014, p. 17).

Respecto al año gravable 2017, considera la DIAN que la utilización de beneficios tributarios por parte de las personas jurídicas se situó en $\$ 12.233 \mathrm{~mm}$ (1,3\% del PIB), con una reducción de 33,1\% frente a lo registrado en el año gravable anterior, como consecuencia de la eliminación establecida en la Ley 1819 de 2016 de varias rentas exentas. En particular, el rubro de rentas exentas mostró una reducción del valor utilizado de 39,7\%, es decir, cerca de $\$ 5.900 \mathrm{~mm}$ menos en el valor del beneficio. En cuanto al costo fiscal, “este ascendió a \$5.277 mm para una variación positiva de 6,5\%, aumento explicado por la presencia de una mayor tarifa del impuesto frente al año anterior (de 25 a $34 \%$ ) y de la existencia de la sobretasa de este, que se traduce en un mayor valor como costo fiscal de las rentas exentas y de la deducción por inversión en activos fijos" (DIAN, 2018, p. 19).

Señalado lo anterior, y con el propósito de observar la incidencia real de las rentas exentas, la DIAN distingue el grupo de grandes contribuyentes, el cual dividió entre las empresas público/mixtas y empresas privadas. Esto, debido a que las exenciones aplicadas por las empresas industriales y comerciales del Estado tienen, según la DIAN, un efecto neutral en el balance del sector público, dado que los menores impuestos inducidos por la exención se traducen en mayores utilidades y, por tanto, en un mayor reconocimiento en el impuesto de renta. Informa la DIAN:

El monto total de las rentas exentas para los grandes contribuyentes ascendió en el año gravable 2013 a $\$ 8.056 \mathrm{~mm}$, que representa un crecimiento del $33,4 \%$ respecto del total registrado durante el año inmediatamente anterior. De este monto, el 76,2\% corresponde a la participación del sector privado y el 23,8\% al sector público/mixto. Con respecto al año gravable 2012, se presentó un notable incremento de las rentas exentas de los grandes contribuyentes del sector público/mixto. (2014, p. 27)

Más allá del impacto fiscal, se debe pensar que una norma disponga una exención tributaria para unos y no para otros, pues, los sujetos o grupos de sujetos en iguales condiciones, a la luz del principio de capacidad de pago, deben como regla ser gravados de manera igual. Es en ese sentido que se debe mirar la mayor participación en el total de las rentas 
exentas de los grandes contribuyentes del sector privado. Esto, recordando que, si bien la exención supone la concesión de un beneficio fiscal, no tiene el carácter de medio extintivo extraordinario de la obligación tributaria. Esta precisión, dada por la Corte Constitucional, indica que la exención se refiere a ciertos supuestos objetivos o subjetivos que integran el hecho imponible, pero cuyo acaecimiento "enerva el nacimiento de la obligación establecida en la norma tributaria” (Sentencia C-511/96). La exención contribuye, en ese sentido, a conformar el contenido y alcance del tributo sin aparejar su negación. Por tanto, da lugar a la realización del hecho imponible pero impide la actualización del impuesto; en cambio, el saneamiento o la amnistía se menciona respecto de obligaciones tributarias perfeccionadas y plenamente exigibles respecto de las cuales, ex ante, no se ha dispuesto por la ley ninguna circunstancia objetiva o subjetiva capaz de reprimir su nacimiento (Sentencia C-511/96).

\section{DEDUCCIÓN POR INVERSIÓN EN ACTIVOS FIJOS PRODUCTIVOS}

La deducción por inversión en activos fijos reales productivos hacía parte de los beneficios contemplados en la legislación tributaria desde el año $2003^{9}$. Este beneficio se otorgaba sobre el $30 \%$ del valor de las inversiones efectivamente realizadas y se hacía por una sola vez en la declaración del periodo en que fueran realizadas, incluyendo las de leasing con opción irrevocable de compra, esto es, cuando debía ejercerse dicha opción y la deducción debía incluirse en la declaración del año en que se suscribió el contrato ${ }^{10}$.

La inversión de activos fijos reales productivos se refiere a "bienes tangibles que se adquieren para formar parte del patrimonio, participan de manera directa y permanente en la actividad productora de renta del contribuyente y se deprecian o amortizan fiscalmente" (Decreto 1766 de 2004, art. 2). La explicación que ofrece el Consejo de Estado para que este tipo de bienes fueran considerados como activos fijos reales productivos, de acuerdo con las normas transcritas, fue la siguiente:

Las personas jurídicas contribuyentes del impuesto sobre la renta que entre el $1^{\circ} \mathrm{de}$ enero de 2004 y el 31 de diciembre de 2007 invirtieran en la adquisición de activos fijos reales productivos, podían deducir el $30 \%$ del costo de adquisición del bien, por una sola vez, en la declaración del periodo en que efectuaron la inversión. Si los bienes eran adquiridos por el sistema leasing, debía ejercerse la opción irrevocable de compra y la deducción debía incluirse en la declaración del año en que se suscribió en el contrato. La deducción no procedía para los contratos de retroarriendo o lease back, ni cuando los bienes eran readquiridos por el contribuyente. Así mismo, para que los bienes

$9 \quad$ Artículo 68 de la Ley 863 de 2003, el cual fue derogado por el artículo 376 de la Ley 1819 de 2016.

10 El artículo 8 de la Ley 1111 de 2006 lo estipuló en 40\%, y el artículo 10 de la Ley 1370 de 2009 vuelve a considerar, a partir del periodo gravable de 2010, la deducción del $30 \%$ del valor de las inversiones efectivas realizadas solo en activos fijos reales productivos. 
fueran considerados como activos fijos reales productivos, se requería que (i) se tratara de activos fijos, (ii) que estos fueran bienes tangibles, (iii) que se adquirieran para formar parte del patrimonio del contribuyente, (iv) que participaran de manera directa y permanente en la actividad productora de renta, y (v) que se depreciaran o amortizaran fiscalmente. Según el artículo 60 del Estatuto Tributario, son activos fijos "los bienes corporales muebles o inmuebles y los incorporales que no se enajenan dentro del giro ordinario de los negocios del contribuyente". (Sentencia 18662)

Como queda claro en la norma tributaria, los que aplicaran a dicho beneficio no podían aplicar al mismo tiempo a otro, por ejemplo, el de auditoría. Esto, como señalaba la Ley 1111 de 2006, indicaba que la deducción por inversión en activos fijos "solo podía aplicarse con ocasión de aquellos activos fijos adquiridos que no hayan sido objeto de transacción alguna entre las demás empresas filiales o vinculadas accionariamente o con la misma composición mayoritaria de accionistas, y la declarante, en el evento en que las hubiere" (art. 8).

Ahora bien, la importancia de lo anotado radica no tanto en el conocimiento del valor de la deducción llevada por el contribuyente y, por ende, de la disminución de la base gravable, sino en su consecuencia, es decir, en la estimación del costo físcal del beneficio, así como la inversión estimada, según la naturaleza del contribuyente, la actividad principal generadora de sus ingresos y su domicilio para efectos fiscales. En otras palabras, la existencia de estos beneficios fiscales que se traducían en reducciones de la base gravable de contribuyentes y que afectaban directamente la liquidación del impuesto, se produjo sobre propósitos diversos que incidían en grupos sociales o sectores específicos de la economía. En esta ocasión, la deducción fue motivada para "estimular la inversión y compensar los costos por efecto de la sobretasa en el impuesto sobre la renta y la adopción transitoria del impuesto al patrimonio" (DIAN, 2006).

Dentro de las notorias mediciones del costo fiscal realizadas por la DIAN, el fisco nacional dejó de percibir recursos considerables, la deducción se hizo efectiva en las declaraciones de renta por parte de 12.885 declarantes, entre personas naturales y jurídicas (DIAN, 2006). Aunque no se puede establecer una relación directa del impacto de la medida sobre el comportamiento de la actividad económica agregada, este beneficio fiscal contribuyó con un clima más favorable para el emprendimiento de nuevas inversiones y negocios. Esto indica que, según la DIAN, los resultados generales de la aplicación de la norma fueron favorables por el incremento de la inversión en la economía del país cercana al $31 \%$, la cual se concentró en tres subsectores económicos: el minero, el de servicios de transporte, almacenamiento y comunicaciones, y el subsector electricidad, gas y vapor (p. 5).

Este ritmo de crecimiento respondió a diversos factores, a saber: las políticas de bajas tasas de interés, la confianza de consumidores e inversionistas y las mejoras en productividad. Esto llevó a la DIAN a considerar que, en el primer año de vigencia, la respuesta de los declarantes superó las expectativas iniciales en la utilización de este instrumento, pues, el resultado había sido una importante compensación respecto al costo fiscal estimado, es 
decir, que si por un lado se duplicó la disminución de los ingresos en el impuesto sobre la renta como efecto del beneficio en la base gravable de los contribuyentes; por otro, la pérdida de recursos se dio por el lado del estímulo a la inversión, lo que contribuyó a la importante dinámica del rubro de inversión agregada que, junto con el consumo privado, constituyeron los factores relevantes para explicar el buen comportamiento de la economía durante 2004 y 2005 (DIAN, 2006, p. 4). Lo anterior, pese a los niveles de desempleo empleo y a que, de acuerdo con el Gini, la distribución del ingreso seguía indicando una redistribución que mantenía la desigualdad, con un coeficiente de 0,561 en 2004, y un 0,553 en 2005 (p. 20).

\section{Descuentos TRIBUtarios}

Otro beneficio en el impuesto de renta que incide directamente sobre la magnitud del impuesto por pagar son los descuentos tributarios (DIAN, 2014, p. 32). En Colombia, la medición de los beneficios tributarios se estableció mediante la Ley 788 de 2002, la cual formuló en su artículo 87 la obligación de presentar "un informe detallado en el que se deberá evaluar y hacer explícito el impacto fiscal de los beneficios". En concordancia con este punto, la Ley 819 de 2003 fijó la elaboración del marco fiscal de mediano plazo, el cual debe contener "una estimación del costo fiscal de las exenciones, deducciones o descuentos tributarios existentes en la Legislación y que anualmente debe acompañar al Proyecto de Presupuesto General de la Nación" (art. 1, lit. f).

Apuntando a un marco más amplio, el porcentaje del impuesto básico de renta en años gravables 2004-2013, muestra que los descuentos tributarios pueden ubicarse en el hecho de que su valor no disminuye la renta gravable sino, directamente, el impuesto por pagar. Entre los de mayor relevancia vale la pena citar los aplicados a los sectores minero; electricidad, gas y vapor; servicios de transporte; comunicaciones; servicios financieros, y el sector de fabricación de productos minerales, por ser estos los más significativos (DIAN, 2014, p. 17). Expresado como porcentaje del PIB de los descuentos tributarios de las personas jurídicas, se evidencia su menor importancia relativa respecto al comportamiento de las rentas exentas y la deducción por inversión en activos fijos reales productivos. No obstante, desde el año gravable 2006 se observa una tendencia ascendente del porcentaje de participación de los descuentos tributarios en el PIB, a excepción del año 2010, cuya proporción alcanzó el 0,09\% del PIB. Para el año gravable 2013, los subsectores de explotación de minas y canteras, actividades financieras y de seguros e industrias manufactureras, son los de mayor importancia en la determinación de este indicador, desplazando con ello al subsector suministro de electricidad, gas, vapor y aire acondicionado, que redujo el uso de este beneficio frente al año inmediatamente anterior (p. 17).

El monto de los descuentos tributarios para las personas jurídicas contribuyentes ascendió a \$764 mm durante el año gravable 2013. Lo anterior equivale a un considerable crecimiento del 8,8\% respecto del año gravable 2012, comportamiento influenciado por los descuentos tributarios utilizados por los subsectores de explotación de minas y 
canteras, comercio, reparación de vehículos automotores y motocicletas, actividades financieras y de seguros. Esto indica que se presentó una disminución en el uso de los descuentos en subsectores como suministro de electricidad, gas, vapor y aire acondicionado; transporte y almacenamiento, relevantes durante el año gravable 2012 y que, a pesar de esta reducción, se conservan dentro de los primeros cinco subsectores de mayor importancia en el uso de este beneficio (DIAN, 2014, p. 28).

Respecto de la incidencia de los descuentos tributarios en el impuesto liquidado, se observa que las personas jurídicas que solicitaron los descuentos mencionados en el año gravable 2013 "lograron reducir su impuesto sobre la renta líquida gravable en $6,8 \%$ en promedio" (DIAN, 2014, p. 29). Si bien este registro es superior al del año anterior es de anotar, como indica la DIAN, que "el impuesto sobre la renta líquida gravable de las personas jurídicas contribuyentes que utilizaron los descuentos tributarios en 2012 y/o 2013 disminuyó $23,4 \%$, asociado a la reducción de la tarifa del impuesto de renta” (p. 29). Se recuerda que los descuentos tributarios estaban representados, en primer lugar, por las rentas exentas con el 78,0\%; en segundo lugar, por la deducción por inversión en activos fijos reales productivos con el $16,7 \%$ y, en tercer lugar, por los descuentos tributarios con $5,3 \%$; esta medición es importante por cuanto sirve para evaluar los efectos del sistema tributario en los ingresos. Según la DIAN, el instrumento cobra mayor importancia si como resultado de esas mediciones se logra vislumbrar a los verdaderos beneficiarios de estos tratamientos excepcionales. En eso se puede estar de acuerdo con la DIAN, sin embargo, lo que sí es discutible de cara a la progresividad es afirmar que "la teoría señala que el efecto inicial de las renuncias tributarias a mediano y largo plazo será una mejora en el bienestar de la sociedad por la vía de los mayores ingresos generados que a la postre los individuos y sectores logran tras el estímulo otorgado inicialmente" (p. 32).

Al igual que en el análisis de rentas exentas, la DIAN diferencia los descuentos tributarios entre aquellos utilizados por el sector público/mix to y el sector privado. Allí observa que la composición pública y privada del monto de descuentos solicitados por las personas jurídicas contribuyentes en el año gravable 2013, se mantiene respecto de la registrada durante el año gravable 2012. No obstante, el sector privado conserva la mayor participación dentro del total de descuentos tributarios con un porcentaje de $83,1 \%$ en tanto que los descuentos efectuados por el sector público/mixto participan con el 16,9\%. Este último sector presenta un descenso cercano al $21,4 \%$ en el uso de los descuentos tributarios, explicados por la reducción exhibida en el subsector de suministro de electricidad, gas, vapor (DIAN, 2014, p. 29).

En el año gravable 2013, la utilización de descuentos tributarios permitió a las personas jurídicas reducir su impuesto sobre la renta líquida gravable en 6,8\% en promedio, como resultado de un aumento en el valor de los descuentos tributarios solicitados frente al año anterior, así como del menor impuesto liquidado fruto de una tarifa nominal del impuesto más bajo que la vigente durante el año gravable 2012 (DIAN, 2014, p. 33). En consecuencia, posee los mismos beneficios adicionales de la renta exenta pero, contrario a aquella, el valor de los descuentos tributarios puede, en algunos casos, exceder 
económicamente al que se obtendría si tuviese el tratamiento de renta exenta. Ese hecho se origina, proporcionalmente, porque los descuentos tributarios (que se aplican como un porcentaje del valor sujeto al beneficio) pueden ser mayores que la tarifa del impuesto de renta, que es el valor máximo al que se tendría derecho si a la partida en cuestión se le otorgara el tratamiento de renta exenta.

Sin lugar a dudas, esto representa un gran impacto en las finanzas de la hacienda pública y, en particular, en la aplicación de la progresividad del sistema. Esto haría apropiado que, aun cuando la Ley 819 de 2003 no cobije el seguimiento a los ingresos no constitutivos de renta ni ganancia ocasional, se determinara su costo fiscal por parte del Gobierno nacional, aplicando los aspectos constitucionales señalados. Para ello, se debería tener presente lo anotado por la DIAN referente al gasto tributario en Colombia en dos sentidos: primero, que "el costo fiscal de los descuentos tributarios en el año gravable 2014 ascendió a $\$ 947 \mathrm{~mm}$, de los cuales $\$ 821 \mathrm{~mm}$ corresponde a personas jurídicas y se estima que $\$ 127$ mm corresponden a descuentos solicitados por las personas naturales" (DIAN, 2015a, p. 14); segundo, que "las estimaciones del gasto tributario se están presentando desde el año 2004 y dentro de los métodos comúnmente más utilizados se optó por el método de pérdida de recaudación con enfoque anual y aplicando el supuesto de comportamiento constante sobre los consumidores" (DIAN, 2014, p. 32). La DIAN concluye que este método no logra mostrar todos los efectos que causa en las declaraciones del impuesto sobre la renta de las personas jurídicas por el año gravable 2013, pues, "los beneficios tributarios ascendieron a $\$ 14.357 \mathrm{~mm}$, estimándose un costo fiscal de $\$ 4.162 \mathrm{~mm}$, que en términos del PIB equivale a $0,6 \%$. Considerando únicamente a los contribuyentes del impuesto, el costo fiscal disminuye a $\$ 3.602 \mathrm{~mm}$ (0,5\% del PIB)" (DIAN, 2014, p. 32).

\section{ZONAS FRANCAS. LA TARIFA DIFERENCIAL DE LAS ZONAS FRANCAS FRENTE A LA GENERAL}

La ley colombiana define una zona franca como un área geográfica delimitada en territorio nacional, donde se desarrollan actividades industriales o actividades comerciales, bajo una normativa especial en materia tributaria, aduanera y de comercio exterior (Ley 1004 de 2005, art. 1) ${ }^{11}$. En lo atinente al desarrollo de actividades industriales o actividades comerciales, estas zonas tienen los siguientes propósitos: primero, "ser instrumento para la creación de empleo y para la captación de nuevas inversiones de capital"; segundo, "ser un polo de desarrollo que promueva la competitividad en las regiones donde se establezca"; tercero, "desarrollar procesos industriales altamente productivos y competitivos, bajo los conceptos de seguridad, transparencia, tecnología, producción limpia, y buenas prácticas empresariales"; cuarto, "promover la generación de economías de escala"; quinto,

11 El modelo de zonas francas nació en Colombia en los años cincuenta con la Ley 105 de 1958, con el objetivo primordial de impulsar las exportaciones dentro de la política de apertura económica de la época. 
"simplificar los procedimientos del comercio de bienes y servicios, para facilitar su venta" (Ley 1004 de 2005, art. 2).

En lo que concierne a la normativa especial en materia tributaria, el propósito ha sido siempre estimular la inversión en estas zonas y, de esta manera, alcanzar la finalidad de estas mediante la estipulación de diferentes tipos de incentivos. El principal, para empresas usuarias del régimen de zona franca, era tener una tarifa del impuesto sobre la renta del $15 \%$, aplicado a la actividad productora exclusiva en esta zona, para los usuarios industriales de bienes y servicios nuevos o existentes y usuarios operadores de zona franca. Este incentivo no aplica para el usuario comercial, pues la tarifa del impuesto sobre la renta gravable aplicable a los usuarios comerciales de zona franca es la tarifa general vigente. Así lo advertía el artículo 5 de la Ley 1004 de 2005, el cual indicaba:

Artículo 240-1. Tarifa para usuarios de Zona Franca. Fijase a partir del $1^{\circ}$. de enero de 2007 , en un quince por ciento (15\%) la tarifa única del impuesto sobre la renta gravable, de las personas jurídicas que sean usuarios de Zona Franca.

Parágrafo. La tarifa del impuesto sobre la renta gravable aplicable a los usuarios comerciales de Zona Franca será la tarifa general vigente. (Énfasis agregado)

No obstante, el artículo 101 de la Ley 1819 de 2016, por medio de la cual se adopta una reforma tributaria estructural, modifica parcialmente la anterior reglamentación al señalar que a partir del 1 de enero de 2017, la tarifa del impuesto sobre la renta y complementarios para las personas jurídicas que sean usuarios de zona franca será del $20 \%$, manteniendo vigente la tarifa general del impuesto sobre la renta gravable aplicable a los usuarios comerciales de estas zonas, según el artículo 240 del Estatuto Tributario. Además, la señalada norma advierte que para los contribuyentes usuarios de zona franca que tienen suscrito contrato de estabilidad jurídica, la tarifa será la establecida en el correspondiente contrato y no podrá aplicarse concurrentemente con la deducción tratada en artículo 158-3 del Estatuto. Por consiguiente, los contribuyentes usuarios de zonas francas que hayan suscrito un contrato de estabilidad jurídica no tendrán derecho a la exoneración de aportes de que trata el artículo 114-1 del Estatuto Tributario (art. 240-1, ET).

Una descripción amplia de incentivos que buscan la inversión, relacionada con el impuesto sobre la renta, y que tiene que ver con otras exenciones y deducciones, es:

- Para las empresas dedicadas a ciencia y tecnología se deduce el $175 \%$ del valor de la inversión que se realice en investigación, desarrollo e innovación, siempre y cuando no exceda el $40 \%$ de la renta líquida (Artículo 158-1: ET).

- Las filiales, subsidiarias o agencias en Colombia de sociedades extranjeras podrán deducir las cantidades que hayan sido pagadas o reconocidas directa o indirectamente en el exterior por concepto de gastos de administración o dirección y por concepto de regalías de explotación o adquisición de cualquier clase de intangibles de los gastos 
incurridos por las casas matrices en el exterior, respecto de gastos de administración. (Artículo 124: ET)

- El $100 \%$, de los salarios pagados a los trabajadores son deducibles; siempre y cuando el empleador se encuentre a paz y salvo por concepto del pago de los aportes parafiscales: ICBF, SENA, Subsidio Familiar. (Artículo 108: ET)

- Es deducible el $100 \%$ de los impuestos de industria y comercio, avisos y tableros y predial, que efectivamente se hayan pagado durante el año o periodo gravable siempre y cuando tengan relación de causalidad con la actividad económica del contribuyente. (Artículo 115: ET)

- El 100\% del valor de las inversiones en control y mejoramiento del medio ambiente, son deducible, pero no pueden exceder el $20 \%$ de la renta líquida gravable (Artículo 158-2: ET)

- No pagan CREE (Impuesto sobre la renta para la equidad), las zonas francas aprobadas al 31 de diciembre del 2012, o aquellas que hayan radicado la respectiva solicitud ante la Comisión Intersectorial de Zonas Francas hasta dicha fecha, y también para los usuarios que se hayan calificado o se califiquen a futuro en estas. Los usuarios industriales de bienes y servicios y usuarios operadores de zona franca que se establezcan en nuevas zonas francas solicitadas o declaradas (permanentes o permanentes especiales: uniempresariales) con posterioridad al 31 de diciembre de 2012, tienen una tarifa del $9 \%$ del CREE.

- Al pagar la sociedad el impuesto de renta sobre las utilidades obtenidas, no se traslada el impuesto a los socios cuando las reciban en forma de dividendo. (Artículos 48,49 y 245: ET)

- Para efectos del impuesto sobre las ventas, conservarán la calidad de bienes y servicios exentos con derecho a devolución bimestral, según lo estipulado en el Artículo 481 del ET: Las materias primas, partes, insumos y bienes terminados que se vendan desde el territorio aduanero nacional a usuarios industriales de bienes o de servicios de zona franca o entre estos, siempre que los mismos sean necesarios para el desarrollo del objeto social de dichos usuarios. (DIAN, 2016, p. 8)

Es innegable que en los últimos años más compañías han buscado calificarse como usuarios del régimen de zona franca como estrategia principal para la promoción de sus negocios, todas, motivadas por los beneficios en materia tributaria, logística y aduanera. Según informa la DIAN, para 2008 había 40 zonas francas declaradas y actualmente más de 100 en todo el país, con un dato significativo de un número mayor de empresas del sector industrial (2016, p. 77). Este aspecto arroja una información considerable para la DIAN. Por un lado, que uno de los aspectos más positivos del régimen es la generación de nuevas empresas y el aumento de las inversiones; por otro lado, en cuanto a la generación de empleo, tiene un balance distinto: para el año 2009, las 64 zonas francas tenían 28.954 empleos directos y 51.576 indirectos; en cambio, a junio de 2016, las zonas francas reportaron un total de 253.053 contratos de empleo en diferentes modalidades. 
Por consiguiente, del total de los 22 millones de ocupados que existen en el país, el empleo generado en las zonas francas representa solo el 1,2\% según cifras del DANE (DIAN, 2016, p. 78).

Para concluir, Colombia es el país de América Latina con el mayor número de zonas francas, y, al mismo tiempo, el que menos empleos genera en comparación con los países que tienen incluso menos cantidad de estas (DIAN, 2016, p. 2). Esto debería ser un motivo para su revisión, pensando en los aspectos constitucionales señalados sobre la equidad en relación con la progresividad del sistema tributario por la tarifa diferencial aplicada.

\section{LOS CONTRATOS DE ESTABILIDAD JURÍDICA}

Con la liberalización de los mercados y la intensa competencia en el mundo globalizado, los Estados han buscado implementar numerosas estrategias con el propósito de motivar la inversión extranjera, estimada fundamental para el crecimiento, el desarrollo y la prosperidad, principalmente en países en vía de desarrollo. Una de esas estrategias concierne a los contratos de estabilidad jurídica frente a la notoria inestabilidad de las normas jurídicas, pues, en materia de inversión se considera casi como un hecho axiomático que "aquellos Estados poseedores de un entorno jurídico claro y estable se encuentran en la delantera de esta competencia debido a que los inversionistas han visto allí una manera de reducir los costos de transacción" (Castaño y Galeano, 2011, p. 70).

Por eso el Estado colombiano, para estimular tanto la inversión nacional como la extranjera, expidió la Ley 963 de 2005 que otorgó al Gobierno y a los inversionistas la posibilidad de suscribir contratos de estabilidad jurídica donde se estipula "el derecho contractual a la estabilidad jurídica de la inversión" (Sentencia C-320/06). Esta estabilidad jurídica no se refiere a una modalidad de contrato que pretenda "congelar las leyes" refiere más bien "a que los derechos que surjan de las inversiones se rijan por las normas vigentes al momento de la celebración del contrato de estabilidad jurídica y no por las leyes posteriores que eventualmente las modifiquen" (DIAN, 2015b, p. 3). En otras palabras, no se refiere a la "inmutabilidad del ordenamiento jurídico, sino de una aplicación de un régimen jurídico, previamente acordado y delimitado en el clausulado del contrato" (Sentencia C-320/06). De allí que la Corte Constitucional haya considerado que el artículo $1^{\circ}$ de la Ley 963 , deba

... ser entendido en el sentido que mediante los contratos de estabilidad jurídica no se garantiza a los inversionistas la inmodificabilidad de la ley, sino que se les asegura

12 La expresión cláusula de congelamiento, usada por la doctrina internacional, ha sido objeto de numerosas críticas a nivel mundial "debido a que el Estado, en ejercicio de su soberanía, podrá en todo momento modificar su legislación y afectar un contrato que se creía protegido con una garantía de inmodificabilidad" (Castaño y Galeano, 2011,p. 71). Precisamente, el artículo 166 de la Ley 1607 de 2012 derogó la Ley 963 de 2005. Parágrafo 2. Los contratos de estabilidad jurídica en ejecución a la fecha de la promulgación de la presente ley continuarán su curso en los precisos términos acordados en el contrato hasta su terminación. 
la permanencia, dentro de los términos del acuerdo celebrado con el Estado, de las mismas condiciones legales existentes al momento de la celebración del contrato. (Sentencia C- 320/06)

Es decir, estos contratos tienen como finalidad evitar que sea alterado el contenido de lo firmado entre el inversionista y el Estado.
Ahora bien, el artículo 1 de la Ley 963 de 2005, estableció que

... mediante estos contratos, el Estado garantiza a los inversionistas que los suscriban, que si durante su vigencia se modifica en forma adversa a estos alguna de las normas que haya sido identificada en los contratos como determinante de la inversión, los inversionistas tendrán derecho a que se les continúen aplicando dichas normas por el término de duración del contrato respectivo ${ }^{13}$. (Énfasis agregado)

Conforme al mencionado artículo, la estabilidad implicaría el congelamiento de las normas estabilizadas solo frente a cambios desfavorables, pero no a los favorables ${ }^{14}$. Por ejemplo, si se estabiliza la tarifa del impuesto sobre la renta del $15 \%$ y la misma se incrementa al $20 \%$, la compañía que gozaba de la estabilidad podría seguir aplicando la tarifa del $15 \%$ durante todo el tiempo pactado; si el cambio se diera en forma inversa, esto es, si se reduce la tarifa del impuesto sobre la renta al 10\%, dicha compañía podría aplicar la tarifa del $10 \%$, amparada no solo en la ley vigente, sino también en las cláusulas del contrato que suscribió (Oundjian, 2009) ${ }^{15}$.

Por lo anterior, la Ley 963 de 2005 logró mantenerse en el propósito de incentivar nuevas inversiones ofreciendo para ello un ordenamiento jurídico estable para los suscriptores de los contratos, de modo que cualquier cambio normativo futuro no afectara de forma negativa al inversionista, pues se mantenía aplicable lo firmado por el término de

13 Es importante anotar que aunque la Ley instauró una estabilidad jurídica para los inversionistas en Colombia, esta estableció claramente que los contribuyentes usuarios de zona franca que tuviesen suscrito contrato de estabilidad jurídica, tendrían como tarifa la establecida en el contrato correspondiente, no pudiendo aplicarse concurrentemente la deducción de la que trataba el artículo 158-3 del Estatuto Tributario.

14 Aunque la Corte Constitucional declaró en la Sentencia C-242 de 2006 que "el Estado garantiza a los inversionistas que los suscriban, que si durante su vigencia se modifica en forma adversa a estos alguna de las normas que haya sido identificada en los contratos como determinante de la inversión, los inversionistas tendrán derecho a que se les continúen aplicando dichas normas por el término de duración del contrato respectivo", dejó a un lado los casos donde la vigencia de la norma se modifica en forma favorable.

15 Respecto a los Instrumentos de Estabilización Jurídica y, en particular, las Cláusulas de Equilibrio Económico, podría consultarse Castaño y Galeano (2011). Igualmente, la DIAN (2015b), mediante concepto 27156 de 17 de septiembre, precisó: "tratándose de un contrato de estabilidad jurídica en donde las partes (Estado-particulares) por el hecho de acordar estabilizar ciertas condiciones jurídicas (normas y tributos vigentes en ese momento) para efectuar y mantener unas inversiones, no puede entenderse que restringe la facultad del Congreso de Colombia para modificar las normas, crear tributos u otorgar exenciones, ni mucho menos que el particular que lo suscribe los pueda hacer oponible ante el fisco para dejar de pagar los impuestos y cumplir las nuevas obligaciones tributarias requeridas para el desarrollo social del país". 
la duración del contrato. Sin embargo, la Ley de estabilidad jurídica estableció una limitación en cuanto a las normas en materia de tributos que pueden ser objeto de estabilización al señalar en su artículo 11 que no podrán serlo aquellas referidas a impuestos indirectos.

Como era de suponer, la utilización de esta figura fue creciente hasta el año 2010, habiéndose suscrito 63 contratos para la fecha, en tanto que para los años 2011 y 2012 se firmaron dos contratos más (DIAN, 2018,p. 37). Con la Ley 1607 de 2012 se derogó la Ley 963 de 2005, y se eliminó así la posibilidad de suscribir nuevos contratos a excepción de las solicitudes que estaban en curso en el Ministerio de Comercio, Industria y Turismo en el momento de entrada en vigencia de la Ley 1607, dejándose presente mantener las condiciones firmadas en los contratos ya vigentes hasta su extinción. En términos jurídicos, todo esto implicó la necesidad de ofrecer mayores facilidades y ventajas a la hora de generar inversión con el compromiso de cumplir las denominadas "reglas de juego" en materia económica y crear una normativa estable que generase menos riesgos políticos (García-Giraldo, 2015, p. 81).

Sin puntualizar el impacto social que resulta frecuentemente asociado a estas disposiciones legales, en el año gravable 2017 se realiza una aproximación de la cuantificación del costo fiscal en el impuesto sobre la renta de los contratos de estabilidad jurídica, empleando como marco de referencia las modificaciones introducidas por la reforma tributaria del año 2016 (Ley 1819). De acuerdo con dicha aproximación, el costo fiscal ascendió a $\$ 1.483 \mathrm{~mm}$, lo que representa el 0,2\% del PIB, concentrándose en la deducción por inversión en activos fijos con el 61,6\% del total. Para las empresas que "estabilizaron el artículo 240 del Estatuto Tributario en el contrato de estabilidad, referente a la tarifa general para personas jurídicas, el costo fiscal se situó en \$34 mm en tanto que para aquellas que estabilizaron el artículo 240-1 del mismo Estatuto (tarifa para usuarios de zona franca) este alcanzó \$246 mm” (DIAN, 2018, p. 42).

De acuerdo con los principios constitucionales del sistema tributario, lo anterior indicaría que los contratos de estabilidad jurídica generan un tratamiento diferente entre las empresas que los suscriben y el resto de las personas jurídicas que no lo hacen, en particular, aquellos mediante ajustes realizados a la estructura tributaria del país. Por ello, cabría preguntar ¿hacia dónde se dirigen estos particulares beneficios? Estos beneficios, básicamente, apuntan en dos direcciones:

... (i) posibilitar un ingreso fluido de inversionistas extranjeros y sus capitales para su incursión en el mercado interno -producción o comercialización- y (ii) posibilitar la configuración jurídica de negocios en el país a través de una configuración societaria sin mayores restricciones, derechos claros y seguros de propiedad o todos aquellos que aseguren una renta, formas contractuales flexibles, claridad en la determinación de posibles daños y su indemnización, el menor control posible de poder en los mercados, propuestas de resolución de conflictos no dilatorias, posibilitar el flujo de recursos humanos y de capital sin mayores requisitos, reducción de cargas impositivas, 
flexibilización de costos laborales y estabilidad y seguridad jurídica. (García-Giraldo, 2015, p. 82)

En efecto, la estabilidad jurídica alude a la permanencia provisional, merced a la suscripción de un contrato estatal, de un determinado marco normativo favorable para las grandes inversiones y, por ende, aquellas que implican un mayor riesgo de pérdida. No se trata, por tanto, de inmutabilidad del ordenamiento jurídico, sino de la aplicación de un régimen jurídico, previamente acordado y delimitado en el clausulado del contrato (Sentencia C-320/06). Por eso, los contratos de estabilidad jurídica tenían como características principales las siguientes:

... (i) se debe indicar de manera taxativa la normativa que se considera determinante al momento de realizarse la inversión; (ii) el valor de la inversión deberá superar el monto establecido por la ley ; (iii) el inversionista debe pagarle al Estado una prima equivalente al $1 \%$ del valor total de la inversión; (iii) la duración del contrato debe ser entre 3 y 20 años; (iv) no son objeto de este contrato la normativa relacionada con seguridad social, normas tributarias dictadas bajo estados de excepción o relativas a los impuestos indirectos, las normas que regulan el sector financiero y las normas que regulan el régimen de tarifas de los servicios públicos. (García-Giraldo, 2015, p. 85)

Así pues, en materia de inversión, podrían concluirse varias cosas: primero, que la solicitud de contrato de estabilidad jurídica debía estar justificada por un compromiso de inversión presente o futura que superase los 7.500 salarios mínimos mensuales legales vigentes, periodo que debía ser claramente definido en la solicitud de aprobación del contrato para realizar la inversión (García-Giraldo, 2015, p. 87).

Segundo, que era posible la eventual modificación del régimen de inversiones teniendo en cuenta un contrato de estabilidad jurídica. Su ocurrencia, si bien no impide su eficacia, traía como consecuencia que los inversionistas pudiesen acudir a las acciones judiciales que estimasen convenientes (Sentencia C-320/06).

Tercero, que el interés primordial de los contratos de estabilidad jurídica es ofrecer a los inversionistas una serie de acciones legales en caso de que el Estado modifique la normativa bajo la cual se firmó el contrato, especialmente en el campo tributario (García-Giraldo, 2015, p. 87).

Cuarto, que si bien este mecanismo "ha caído en desuso a favor de las más modernas cláusulas de equilibrio económico", se requiere una necesaria armonización entre los intereses estatales y los del inversionista extranjero, sobre todo para analizar cómo ha sido su implementación en los países latinoamericanos que se acogieron, como Colombia en su momento, a esta figura jurídica (García-Giraldo, 2015, p. 89).

Quinto, que si bien la ejecución de esta figura ha permitido que se establezcan una serie de garantías y derechos tales como la invariabilidad de regímenes tributarios, la transferencia libre de capital u otras formas de inversión, no obstante, "al igual que ocurre con 
cualquier mecanismo para promover las inversiones, la estabilidad jurídica requiere del acompañamiento de otra serie de incentivos como son: la fortaleza institucional; la credibilidad de su población en las autoridades; el nivel de competitividad y la capacitación del recurso humano" (García-Giraldo, 2015, p. 93).

Por último, que si bien la inversión extranjera se considera indispensable para el desarrollo de un país, la jurisprudencia, tanto en la Sentencia C-242 de 2006 como en la Sentencia C-320 de 2006, hizo una interpretación literal donde aludió únicamente a la garantía otorgada a los inversionistas, frente a las reformas tributarias adversas pero no favorables, dejando con ello una puerta abierta a la regresividad fiscal.

\section{LA AMNISTÍA TRIBUTARIA}

La jurisprudencia constitucional ha señalado que las amnistías tributarias erosionan la justicia y la equidad tributaria cuando son una práctica constante, particularmente, porque la equidad se desconoce si se deja de lado el principio de igualdad en las cargas públicas (Sentencia C-833/13). Respecto a los privilegios otorgados al contribuyente moroso, la jurisprudencia constitucional ha señalado puntualmente lo siguiente:

La condición de moroso no puede ser título para ver reducida la carga tributaria. La ley posterior retroactivamente está produciendo una inequitativa distribución del esfuerzo tributario que se supone fue establecido de manera igualitaria. La reasignación de la carga tributaria paradójicamente favorece a quienes incurrieron en mora y se acentúa en términos reales respecto de quienes observaron la ley. (Sentencias C-511/96; C-1115/01 y C-922/01) ${ }^{16}$

Las fuentes normativas de índole constitucional que sustentan la prohibición de las amnistías tributarias se encuentran en el artículo 95 numeral 9 de la Constitución, que prescribe como deber de la persona y el ciudadano contribuir al financiamiento de los gastos del Estado. Según esta perspectiva normativa, una previsión legal que suprima ese deber en una situación concreta se presume inconstitucional, salvo que cumpla con un juicio estricto para su validez excepcional. Por tanto, resulta ilógico que la ley sea la causa que suprima el deber de pagar a tiempo los impuestos. Ello se produce porque en el largo plazo son un efecto desalentador en relación con los contribuyentes que cumplen la ley, además, porque respecto de los que escamotean el pago de sus obligaciones, son un efecto de irresistible estímulo para seguir haciéndolo (Sentencia C-511/96).

16 En la Sentencia C-511 de 1996, la Corte hace énfasis en que los problemas de eficiencia del aparato estatal no pueden resolverse a costa de la igualdad tributaria y de la abdicación del Estado de derecho. Las autoridades, que están instituidas para asegurar el cumplimiento de los deberes sociales de los particulares, se ven compelidas por la ley a resignar de esta función, no negociable, con el objeto de superar las falencias que exhiben en materia de recaudo, las que debían resolverse a través de otros medios. 
La jurisprudencia constitucional define la amnistía tributaria como modalidad extintiva del deber fiscal en la que opera una condición o remisión de una obligación tributaria preexistente. Por consiguiente, se diferencia de las exenciones porque se aplica cuando, luego de haberse configurado la obligación del sujeto pasivo y encontrándose pendiente del cumplimiento de esta, se le condona el pago de sumas que debía asumir por concepto de obligación, sanción, intereses, etc. Así, "mientras las exenciones operan de manera anticipada, evitando que se genere el gravamen, en el caso de la amnistía se está condonando una obligación tributaria que ya se ha causado" (Sentencia C-833/13). De ese modo, podría decirse que la previsión legal que elimine una obligación tributaria o que otorgue un tratamiento más beneficioso a quienes han incumplido con el deber fiscal es inequitativa y contraria al orden justo, puesto que constituye un perjuicio frente a los contribuyentes cumplidos. Respecto a lo señalado, la jurisprudencia constitucional ha anotado que

... se pervierte la regla de justicia, que ordena tratar a los iguales de modo igual y a los desiguales de modo desigual. En efecto, el criterio que introduce el legislador para conceder el beneficio es el estado de mora del deudor, de suerte que al desacatar con esta decisión el principio de imparcialidad, la aplicación de la norma inexorablemente conduce a una situación inequitativa, como que quienes cumplieron oportuna y fielmente con su deber de tributar son tratados peor que los que no lo hicieron. (Sentencia C-833/13).

En la misma sentencia, la Corte Constitucional declaró inexequible la norma que establecía medidas de saneamiento respecto de activos omitidos y pasivos inexistentes en declaraciones de renta y complementarios, al concluir que los beneficios allí previstos configuraban una amnistía tributaria injustificada. Para arribar a esta decisión en escenarios en los que se está ante una amnistía tributaria, así como las condiciones para su validez constitucional, la Corte planteó las siguientes premisas:

Al margen de la denominación del beneficio tributario, se está ante una amnistía cuando, ante el incumplimiento de obligaciones tributarias, se introducen medidas ya sea para condonar, de manera total o parcial, dicha obligación, o bien para inhibir o atenuar las consecuencias adversas (investigaciones, liquidaciones, sanciones), derivadas de tal incumplimiento. Estas medidas buscan generar un incentivo para que el contribuyente moroso se ponga al día con sus obligaciones y ajuste su situación fiscal a la realidad. En ese sentido, se predica una amnistía tributaria cuando el beneficio opera con posterioridad a la exigibilidad de la obligación fiscal. (Sentencia C-833/13)

De acuerdo con las conclusiones señaladas por la Corte, aunque en el corto plazo las amnistías concurren en el cumplimiento de fines constitucionalmente valiosos, en especial el aumento del recaudo, la ampliación de la base tributaria y el ahorro de recursos públicos utilizados en las labores de fiscalización y sanción, su uso recurrente genera un 
desincentivo para el pago oportuno de las obligaciones tributarias, ante la expectativa de una legislación futura que confiera beneficios a quienes han incurrido en mora. Así, desde la perspectiva del actor racional de mercado y ante la proliferación de normas fiscales con efectos de amnistía, la postura más conveniente sería incurrir en mora, en abierta contradicción con el deber constitucional de tributar. En ese orden de ideas, la validez constitucional de la amnistía no puede estar fundamentada en el logro de mayores ingresos fiscales o en el aumento de la eficiencia y eficacia del recaudo, sino en una justificación que supere las condiciones de un juicio estricto de proporcionalidad. Así lo expresa la Corte al señalar que

... corresponde al legislador acreditar la existencia de una situación excepcional que amerite la adopción de este instrumento de política fiscal, como también aportar elementos que evidencien la idoneidad y necesidad, e igualmente que la afectación que de ella pueda derivarse para los principios de igualdad, equidad y justicia tributaria se vea compensada por su contribución para superar la situación excepcional que se busca afrontar a través de la amnistía tributaria. Allí donde el legislador no aporte tal justificación, en todo caso corresponde a la Corte examinar la constitucionalidad de la medida, para lo cual ha empleado el test de razonabilidad o principio de proporcionalidad. (Sentencia C-833/13)

A partir de lo enunciado, la jurisprudencia constitucional ha declarado la inexequibilidad de medidas legislativas que resultan genéricas al no fundarse en situaciones excepcionalmente específicas, por lo que terminan beneficiando indiscriminadamente a quienes han faltado a sus obligaciones tributarias por no declarar la integridad de su patrimonio o no pagar a tiempo sus impuestos, a través de un tratamiento más benigno del que se dispensa a los contribuyentes cumplidos; o prevén un tratamiento más favorable a los deudores morosos que no realizan ningún esfuerzo para ponerse al día, en contraposición a los contribuyentes que manifiestan su voluntad para suscribir acuerdos de pago para el saneamiento de sus obligaciones vencidas. En contraste, la jurisprudencia constitucional ha declarado la constitucionalidad de normas que, primero, confieren estímulos tributarios de índole coyuntural y con el fin de fomentar una actividad económica en situación de crisis; segundo, alivian la situación de los deudores morosos, sin que la medida legislativa les confiera un tratamiento fiscal más beneficioso que los aplicables a los contribuyentes cumplidos; tercero, permiten la inclusión en la base gravable de activos omitidos o pasivos inexistentes, a condición de que les imponga un régimen impositivo más gravoso del que habría correspondido si hubiesen sido declarados oportunamente y sin renunciar a la aplicación de sanciones (Sentencia C-833/13).

De lo anterior se puede afirmar que una ley que pretenda conceder a los contribuyentes morosos una oportunidad para resolver su situación fiscal no viola la Constitución. Tampoco quebranta la norma fundamental que el Estado haga uso de ciertos instrumentos de recaudo, con el objeto de recuperar, así sea parcialmente, sus créditos, máxime si de ello 
se sigue el aumento de personas que ingresan a la base de contribuyentes. Esto, por cuanto corresponde al Estado recaudar los impuestos dejados de pagar disponiendo, para tal propósito, de herramientas administrativas y judiciales que, ejercidas con eficiencia, seguramente pueden redundar en la recuperación de las acreencias insatisfechas. No obstante, los problemas de eficiencia o eficacia del aparato estatal no pueden resolverse a costa de la igualdad tributaria y de la abdicación del Estado de derecho, pues, en materia tributaria, la eficacia no debe desplazar la primacía que por regla general debe mantener la equidad (Sentencia C-511/96).

En conclusión, las amnistías tributarias resultan, prima facie, inconstitucionales en tanto son contrarias al deber constitucional de tributar y dado que comprometen los principios del sistema tributario de igualdad, equidad y justicia, particularmente porque "los incentivos previstos para que los contribuyentes incumplidos se pongan al día con el fisco pueden llegar a desequilibrar el reparto equitativo de las cargas públicas, en detrimento de quienes han satisfecho de manera completa y oportuna sus obligaciones" (Sentencia C-833/13). No obstante, como indica la sentencia mencionada, dichas amnistías pueden ser excepcionalmente compatibles con la Carta Política, "cuando superen un juicio estricto de proporcionalidad, en el que se demuestre que (i) la medida legislativa es imprescindible para cumplir con fines constitucionales imperiosos; o (ii) los efectos de la amnistía tributaria resulten neutros en relación con el tratamiento fiscal que reciben los contribuyentes cumplidos".

\section{Conclusiones}

El sistema tributario colombiano no ha dado aplicación plena al principio de equidad al dar preeminencia a otros fines económicos. Con ello se va desfigurando la naturaleza y el fin del impuesto sobre la renta dentro de dicho sistema, haciendo inoperantes las manifestaciones del derecho fundamental de igualdad. Estos fines se han convertido en excusa común para formular prescripciones legales que no garantizan tratamientos tributarios diferenciados y justificados.

Sobre el principio de progresividad, el legislador no ha superado la deficiencia que se presenta, en todos los niveles, de compensar una relación simplemente porcentual entre la capacidad económica del contribuyente y el monto de los impuestos a su cargo. En un sentido amplio, no se evidencia la capacidad de un tributo para lograr como fruto de su aplicación una redistribución del ingreso que promueva la equidad. Esto, no solo por la estática desigualdad, sino en razón a que el criterio de capacidad económica prohíbe que el orden jurídico aplique beneficios tributarios en exceso. Por eso, tanto en sentido vertical como horizontal, la progresividad es contraria al sistema.

El sistema tributario, como componente medular de justicia tributaria, se ve afectado por la ineficiencia en el recaudo de los tributos. El incumplimiento de las obligaciones impositivas ha generado una injusta distribución de la carga fiscal que ha conducido a que el sostenimiento de los gastos e inversiones públicas solo se haga a costa de los 
contribuyentes cumplidos. No obstante, la pretensión de asegurar un efectivo control de la recaudación y garantizar la protección a los contribuyentes del poder impositivo debe pensarse principalmente desde la aplicación de beneficios y la práctica misma de la elusión fiscal, que son otros factores que afectan la eficiencia del sistema.

La principal función de la política fiscal debe ser la redistribución, no en el gasto, sobre todo cuando no hay garantía de que este beneficia a todos por igual. De ahí que los esfuerzos deban estar enfocados en descubrir las capacidades reales contributivas de las personas y procurar mayor justicia en el cumplimiento del deber, sin conceder mayor interés a la equidad vertical para analizar la progresividad de un tributo, olvidando examinar sus implicaciones sobre la equidad horizontal. Para promover mayores niveles de bienestar social se ha de buscar, por tanto, la redistribución del ingreso desde el tributo, evitando que la estructura de financiamiento recaiga en mayor medida sobre los estratos medios y bajos. De lo contrario, el tributo no se podrá convertir en el principal instrumento para garantizar un orden económico y social justo.

No es razonable aseverar que la regresividad es inexistente en el sistema representado por tributos como la renta o el IVA, simplemente por considerar que son los tributos más representativos, es decir, por provenir más del $50 \%$ de los recaudos tributarios. Desde esa perspectiva, no se logra ver con claridad si estos necesariamente causan un deterioro en la concentración de la renta, ni tampoco podrá afirmarse de manera categórica que causen la progresividad del sistema de tributación. El análisis de equidad y progresividad no se debe limitar a un tributo en particular, sino en razón del sistema tributario, es decir, del conjunto. Esto permitirá hacer un análisis de relaciones costos fiscales-beneficios sociales implícitos en dichos tributos como en los beneficios tributarios, que han sido instrumento para incentivar determinados sectores económicos y privilegiar el desequilibrio social.

Las estimaciones señaladas del costo fiscal causadas por los beneficios tributarios se están presentando desde el año 2004 dentro del método de pérdida de recaudación con enfoque anual. Este método no logra visibilizar los efectos causados por los beneficios tributarios en la economía y la sociedad, puesto que solo puede concluirse si el costo fiscal aumentó o disminuyó. En otros términos, solo será útil para sondear el costo en el recaudo, su impacto en el gasto público y qué sectores económicos se vieron beneficiados, pero no para evaluar los niveles de concentración de la renta.

La jurisprudencia ha admitido que son idóneas tanto las tarifas diferenciales como las proporcionales para lograr un equilibrio de los principios, particularmente, la progresividad. Sin embargo, aunque no se puede negar que esta sería una propuesta que apunta a corregir el sistema y no un impuesto en particular, ha faltado claridad sobre la complejidad de la tarifa, olvidando que esta puede causar igualmente dificultades en la aplicación de los principios del sistema tributario. Se puede proponer un esquema de progresividad consistente en adoptar un número reducido de tarifas o pensar en un sistema de tarifas marginales que dan lugar a infinitas tarifas efectivas, o en tarifas marginales crecientes. En este caso se trata, evidentemente, de un impuesto progresivo con equidad vertical, que no tiene las discontinuidades de un tributo uniforme y escalonado. Empero, existe una 
dificultad técnica en esta propuesta, pues, además de que no presenta razonables costos administrativos, en la práctica surgen discontinuidades indeseables, pues, las distintas tarifas se pueden presentar en medio de estímulos para reducir la renta, de modo que se podrá trasladar un tramo gravado con una tarifa menor y maximizar el ingreso disponible mediante la reducción de impuestos. En otras palabras, aún dentro de este esquema se pueden desnaturalizar tanto la equidad horizontal como la vertical.

\section{Referencias}

Acosta M. (2018, 11 de mayo). La iniquidad e inequidad tributaria. La República. https://www.larepublica.co/analisis/amylkar-d-acosta-m-557896/la-iniquidade-inequidad-tributaria-2713671

Bautista, J. A. (2011). Equidad o inequidad tributaria en Colombia: 1990-2002. Cuadernos de Contabilidad, 12(30), 45-76.

Castaño, J. y Galeano, P. (2011). Los contratos de estabilidad jurídica en Colombia: ¿una verdadera herramienta para la protección de los intereses del inversionista extranjero y del Estado colombiano? EAFIT Journal of International Law, 2(01), 68-106.

Departamento Nacional de Planeación (DNP) (2006). Hacia una Colombia equitativa e incluyente. Informe de Colombia Objetivos de Desarrollo del Milenio. DNP.

Dirección de Impuestos y Aduanas Nacionales (DIAN) (2006a). Efecto de la deducción por inversión en activos fijos reales productivos en el impuesto sobre la renta. Año gravable 2005. Oficina de Estudios Económicos, Cuaderno de Trabajo.

Dirección de Impuestos y Aduanas Nacionales (DIAN) (2006b). La progresividad del sistema tributario colombiano del orden nacional: un análisis para el IVA y el impuesto sobre la renta. Oficina de Estudios Económicos. Cuaderno de Trabajo.

Dirección de Impuestos y Aduanas Nacionales (DIAN) (2014). El gasto tributario en Colombia. Beneficios en el impuesto sobre la renta-personas jurídicas. Años gravables 2012 y 2013. Coordinación de Estudios Económicos.

Dirección de Impuestos y Aduanas Nacionales (DIAN) (2015a). Beneficios tributarios en el impuesto sobre la renta, en el impuesto sobre la renta para la equidad CREE y en el impuesto al valor agregado (IVA) - año gravable 2014. Coordinación de Estudios Económicos. 
Dirección de Impuestos y Aduanas Nacionales (DIAN) (2015b). Contratos de Estabilidad Jurídica. Concepto 27156 del 17 de septiembre, 1-6.

Dirección de Impuestos y Aduanas Nacionales (DIAN) (2016). Caracterización del régimen de zonas francas en Colombia. Cuadernos de Trabajo. Coordinación de estudios económicos.

Dirección de Impuestos y Aduanas Nacionales (DIAN) (2018). Beneficios tributarios en el impuesto sobre la renta y en el impuesto al valor agregado (IVA) - año gravable 2017. Cuaderno de Trabajo No. 67.

García-Giraldo, J. (2015). Los contratos de estabilidad jurídica en una economía global, un análisis de derecho comparado para el caso de Colombia, Perú y Chile. Revista Jurídicas, 12(1), 78-95.

González, J. I. y Corredor, F. (2016). La reforma tributaria no es estructural, ni integral, ni progresiva. Revista de Economía Institucional, 18(34), 173-200. http://dx.doi. org/10.18601/01245996.v18n34.11.

Jiménez, J. P. (2015). Desigualdad, concentración del ingreso y tributación sobre las altas rentas en América Latina. CEF, Cepal.

Oundjian, A. (2009). Hacia la promoción eficaz de la inversión: los contratos de estabilidad jurídica. Revista Universidad Externado. https://revistas.uexternado.edu.co/ index.php/fiscal/article/download/2743/2388/.

Piza Rodríguez, J. R. (2003). Capacidad económica como principio del sistema tributario. Revista de Derecho Fiscal, 62-76.

Piza Rodríguez, J. R. (2010). Curso de derecho tributario, procedimiento y régimen sancionatorio. Universidad Externado de Colombia.

Plazas Vega, M. (2018). El sistema tributario en el siglo XXI. Temis.

Sierra, P. (2006). Efecto de la deducción del $30 \%$ por inversión en activos fijos reales en el recaudo del impuesto sobre la renta en Colombia en el año gravable 2004. Cuadernos de Trabajo 010. DIAN.

\section{Normatividad}

Congreso de Colombia. Ley 819 de 2003. Diario Oficial 45.243. 
Congreso de Colombia. Ley 1004 de 2005. Diario Oficial 46.138.

Congreso de Colombia. Ley 963 de 2005. Diario Oficial 45.963.

Congreso de Colombia. Ley 1430 de 2010. Diario Oficial 47.937.

Congreso de Colombia. Ley 1607 de 2012. Diario Oficial 48.655.

Congreso de Colombia. Ley 1819 de 2016. Diario Oficial 50.101.

Gobierno de Colombia. Constitución Política de Colombia.

\section{Jurisprudencia}

Consejo de Estado. Sentencia 18662 de 2012 (C.P. Martha Teresa Briceño de Valencia).

Consejo de Estado. Sentencia 250002337000-2012-00413-01 [20970] (C.P. Jorge Octavio Ramírez Ramírez; 9 de marzo de 2017).

Corte Constitucional de Colombia Sentencia C-419 de 1995 (M.P. Antonio Barrera Carbonell).

Corte Constitucional de Colombia. Sentencia C-511 de 1996 (M.P. Antonio Barrera Carbonell).

Corte Constitucional de Colombia. Sentencia C-690 de 1996 (M.P. Alejandro Martínez Caballero).

Corte Constitucional de Colombia. Sentencia C-992 de 2001 (M.P. Rodrigo Escobar Gil).

Corte Constitucional de Colombia. Sentencia C-734 de 2002 (M.P. Manuel José Cepeda Espinosa).

Corte Constitucional de Colombia. Sentencia C-776 de 2003 (M.P. Manuel José Cepeda Espinosa).

Corte constitucional de Colombia. Sentencia C-032 de 2005 (M.P. Jaime Córdoba Triviño).

Corte Constitucional de Colombia. Sentencia C-242 de 2006 (M.P. Clara Inés Vargas Hernández). 
Corte Constitucional de Colombia. Sentencia C-320 de 2006 (M.P. Humberto Antonio Sierra Porto).

Corte Constitucional de Colombia. Sentencia C-891 de 2012 (M.P. Jorge Ignacio Pretelt Chaljub).

Corte Constitucional de Colombia. Sentencia C-209 de 2016 (M.P. Jorge Iván Palacio Palacio).

Corte Constutucional de Colombia. Sentencia C-333 de 1993 (M.P. Eduardo Cifuentes Muñoz).

Corte Constitucional de Colombia. Sentencia C-1115 de 2001 (M.P. Marco Gerardo Monroy Cabra).

Fecha de recepción: junio 9 de 2020

Aprobación par 1: junio 16 de 2020

Aprobación par 2: julio 16 de 2020 